\title{
Optimal Tuning of Decentralized PI Controller of Nonlinear Multivariable Process Using Archival Based Multiobjective Particle Swarm Optimization
}

\author{
R. Kotteeswaran ${ }^{1}$ and L. Sivakumar ${ }^{2}$ \\ ${ }^{1}$ Department of Instrumentation and Control Engineering, St. Joseph's College of Engineering, Chennai 600119, India \\ ${ }^{2}$ Electrical Sciences, Sri Krishna College of Engineering and Technology, Coimbatore, Tamilnadu 641008, India
}

Correspondence should be addressed to R. Kotteeswaran; kotteswaran@gmail.com

Received 31 May 2013; Revised 3 December 2013; Accepted 4 December 2013; Published 12 February 2014

Academic Editor: Nikos D. Lagaros

Copyright (c) 2014 R. Kotteeswaran and L. Sivakumar. This is an open access article distributed under the Creative Commons Attribution License, which permits unrestricted use, distribution, and reproduction in any medium, provided the original work is properly cited.

\begin{abstract}
A Multiobjective Particle Swarm Optimization (MOPSO) algorithm is proposed to fine-tune the baseline PI controller parameters of Alstom gasifier. The existing baseline PI controller is not able to meet the performance requirements of Alstom gasifier for sinusoidal pressure disturbance at $0 \%$ load. This is considered the major drawback of controller design. A best optimal solution for Alstom gasifier is obtained from a set of nondominated solutions using MOPSO algorithm. Performance of gasifier is investigated at all load conditions. The controller with optimized controller parameters meets all the performance requirements at $0 \%, 50 \%$, and $100 \%$ load conditions. The investigations are also extended for variations in coal quality, which shows an improved stability of the gasifier over a wide range of coal quality variations.
\end{abstract}

\section{Introduction}

Integrated Gasification Combined Cycle (IGCC) is an efficient method of clean power and energy generation. Here coal reacts with air and steam which is converted into producer gas (also called syngas) under controlled pressure and temperature. Purified producer gas is directed to gas turbine for generating power. The exhaust gas from the gas turbine enters Heat Recovery Steam Generator (HRSG) to produce steam which in turn runs the steam turbine, coupled with a generator. Coal gasifier is an important and primary element in IGCC. It involves many complicated chemical reactions with huge time constant, interactions among the control loop, and strong nonlinearity. The benchmark model of coal gasifier was developed in two stages at the Alstom Technology Centre, UK. The linear gasifier model at $0 \%, 50 \%$, and $100 \%$ load conditions was issued in 1997. The details of this model, its specifications, and control techniques are discussed in the literature [1-8]. A nonlinear model which includes load change test and coal quality variation test is issued as second round challenge pack in 2002 [9] and a special session is held at UKACC CONTROL 2004 Conference [10].
The baseline controller [2] provided with the challenge pack fails to satisfy the constraints [11] at $0 \%$ load for sinusoidal pressure disturbance. The ultimate requirement is to design a suitable controller such that each of the constraint is met for all load conditions.

Researchers have attempted to design advanced control schemes and/or retune the baseline controller to meet the performance objectives at $0 \%, 50 \%$, and $100 \%$ load conditions. This benchmark challenge II, which is a higher order state space model, is reduced to lower order model by different techniques $[12,13]$. Design and implementation of advanced control schemes are also reported in the literature [14-23]. Soft computing techniques such as Bat algorithm, Cuckoo search, Nondominated Sorting Genetic algorithm II, Multiobjective Genetic algorithm, and Normalized Normal Constraint algorithm are also found in the literature $[6,7]$, [22-28], which deals with tuning of baseline PI controller. Cuckoo search algorithm [24] and Bat algorithm [25] are used to retune a portion of baseline PI controller (pressure loop PI controller) since the baseline PI controller did not satisfy PGAS constraints at $0 \%$ load for sinusoidal pressure disturbance. Improved results are obtained for pressure 
disturbance test and coal quality variation test when compared to baseline PI controller. Further, in order to improve the overall response during pressure disturbance and coal quality variations, all four loops are retuned using multiobjective optimization techniques $[22,27,28]$. The performance of the gasifier is improved during pressure disturbance test and coal quality variation test. Recent development in soft computing approaches offers the scope for new optimization algorithms to be used with this problem. Archival based Particle Swarm Optimization (PSO) algorithm, one of such improved versions of PSO, finds many successful applications in all fields of engineering with single objective and multiobjective optimization problems. In the present work, PSO based Multiobjective Optimization algorithm is used to finetune the parameters of baseline PI controller. The simulation results are compared with baseline PI [11], Simm A [22], Cuckoo PI [24], and Bat PI [25].

\section{Controller Structure and Input/Output Limits}

Coal gasifier is a highly nonlinear, multivariable process, having five controllable inputs (char flow rate, air flow rate, coal flow rate, steam flow rate, and limestone flow rate), few noncontrol inputs (boundary conditions, pressure disturbance, and coal quality), and four outputs (fuel gas calorific value, bed mass, fuel gas pressure, and fuel gas temperature) with a high degree of cross-coupling between them. The process is a four-input, four-output regulatory problem for the controller design with limestone flow rate at a constant value. Coal gasifier exhibits a complex dynamic behaviour with mixed, fast, and slow dynamics and it is difficult to control. The complete transfer function of coal gasifier is expressed as

$$
\left[\begin{array}{l}
y_{1} \\
y_{2} \\
y_{3} \\
y_{4}
\end{array}\right]=\left[\begin{array}{lllll}
G_{11} & G_{12} & G_{13} & G_{14} & G_{15} \\
G_{21} & G_{22} & G_{23} & G_{24} & G_{25} \\
G_{31} & G_{32} & G_{33} & G_{34} & G_{35} \\
G_{41} & G_{42} & G_{43} & G_{44} & G_{45}
\end{array}\right]\left[\begin{array}{l}
u_{1} \\
u_{2} \\
u_{3} \\
u_{4} \\
u_{5}
\end{array}\right]+\left[\begin{array}{l}
G_{d 1} \\
G_{d 2} \\
G_{d 3} \\
G_{d 4}
\end{array}\right] \times d
$$

where $y_{1}=$ CVGAS $=$ fuel gas caloric value $(\mathrm{J} / \mathrm{kg}), y_{2}=$ MASS $=$ bed mass $(\mathrm{kg}), y_{3}=$ PGAS $=$ fuel gas pressure $\left(\mathrm{N} / \mathrm{m}^{2}\right), y_{4}$ $=$ TGAS = fuel gas temperature $(\mathrm{K}), G_{i j}=$ transfer function from $i$ th input to $j$ th output, $u_{1}=\mathrm{WCHR}=$ char extraction flow $(\mathrm{kg} / \mathrm{s}), u_{2}=$ WAIR $=$ air inlet flow $(\mathrm{kg} / \mathrm{s}), u_{3}=$ WCOL $=$ coal inlet flow $(\mathrm{kg} / \mathrm{s}), u_{4}=$ WSTM = steam inlet flow $(\mathrm{kg} / \mathrm{s})$, $u_{5}=$ WSLM $=$ limestone mass flow $(\mathrm{kg} / \mathrm{s})$, and $d=$ PSINK = sink pressure $\left(\mathrm{N} / \mathrm{m}^{2}\right)$.

The order of Alstom gasifier is found to be 25. The process is reduced to $4 \times 4$ square matrix, since limestone flow rate is kept constant which is approximated to $1 / 10$ th of flow rate of coal. The existing baseline controller structure is given in Table 1. It employs three PI controllers and one feedforward plus feedback controller for regulating the outputs. The output variables CVGAS, PGAS, and TGAS are controlled by the inputs WAIR, WSTM, and WCHR, respectively, while WCOL (feedback) and WCHR (feedforward) regulate MASS.
TABLE 1: Controller structure.

\begin{tabular}{lcccc}
\hline & WCHR & WAIR & WCOL & WSTM \\
\hline CVGAS & 0 & PI & 0 & 0 \\
MASS & P & & P & 0 \\
PGAS & 0 & 0 & (Feedback) & \\
TGAS & PI & 0 & 0 & PI \\
\hline
\end{tabular}

TABLE 2: Input limits.

\begin{tabular}{lccc}
\hline Input variable & Max. $(\mathrm{kg} / \mathrm{s})$ & Min. $(\mathrm{kg} / \mathrm{s})$ & Rate $\left(\mathrm{kg} / \mathrm{s}^{2}\right)$ \\
\hline WCHR & 3.5 & 0 & 0.2 \\
WAIR & 20 & 0 & 1.0 \\
WCOL & 10 & 0 & 0.2 \\
WSTM & 6.0 & 0 & 1.0 \\
\hline
\end{tabular}

TABle 3: Output limits.

\begin{tabular}{lcc}
\hline Output variable & Desirable & Limits \\
\hline CVGAS & & $\pm 10 \mathrm{~kJ} \mathrm{~kg}^{-1}$ \\
MASS & Minimize & $\pm 500 \mathrm{~kg}$ \\
PGAS & fluctuations & $\pm 0.1 \mathrm{bar}$ \\
TGAS & & $\pm 1 \mathrm{~K}$ \\
\hline
\end{tabular}

The structure of PI controller is given by

$$
u(s)=K_{c}\left(1+\frac{1}{s T_{i}}\right) e(s),
$$

where $u(s), K_{c}, T_{i}$, and $e(s)$ are the controller output, proportional gain, integral time, and error signal, respectively. Controller parameters are determined by considering the following input and output constraints. The input actuator flow limits and rate of change of limit are associated with the physical properties of the actuator. Hence, the inputs should not exceed the value shown in Table 2.

Gasifier outputs should be regulated within the limits for sink pressure (PSINK) disturbance test (Table 3). During load change and coal quality variation tests, the outputs should be regulated as closely as possible to the demand.

\section{Multiobjective Particle Swarm Optimization (MOPSO)}

Multiobjective optimization involves two or more objectives that are optimized simultaneously. The discussions about various multiobjective evolutionary approaches from analytical weighted aggression to population based approaches and Pareto-optimality concepts are discussed by Fonseca and Fleming [29]. Pareto based approaches are most suitable for multiobjective optimization problems, due to their ability to produce multiple solutions in less computation time. Nondominated Sorting Genetic algorithm II (NSGA II) [30], Pareto Archive Evolutionary Strategy (PAES) [31], and Microgenetic Algorithm (micro-GA) [32] are the three highly competitive Evolutionary Multiobjective (EMO) algorithms used in the recent past. Further, PSO [33] based algorithms 
seem particularly suitable for single and multiobjective optimization, because of their high speed of convergence. PSO has been used widely in optimising the outputs of process industries $[34,35]$. There are several forms of multiobjective PSO proposed over the years, to solve multiobjective problems. Coello [36] proposed a Pareto dominance based MOPSO approach to solve multiobjective optimization problems.

Mathematically,

minimize

$$
f_{i}(x), \quad i=1,2, \ldots, M
$$

subject to the constraints

$$
\begin{gathered}
h_{j}(x)=0, \quad j=1,2, \ldots, J, \\
g_{k}(x) \leq 0, \quad k=1,2, \ldots, K,
\end{gathered}
$$

where the constraints $h_{j}(x)$ and $g_{k}(x)$ represent the restrictions imposed on the decision variables and $x$ denotes the optimum solution. The decision vector $x=\left(x_{1}, x_{2}, \ldots, x_{n}\right)$ can be discrete, continuous, or mixed in $n$ dimensional space. The functions $f_{i}$ are called objective or cost function. When $M$ is greater than one, the optimization is termed as multiobjective or multicriteria. Figure 1 shows the flow chart for MOPSO scheme. In addition to the repository of particles and mutation operator, this algorithm uses secondary repository of particles to guide the other particles. External repository stores the record of all nondominated solutions found during the search process. The external repository contains archive controller and grid. Archive controller decides the inclusion of certain solution into the archive.

3.1. Flow Chart. Nondominated vectors acquired in the primary population are compared with the elements of external repository which will be empty at the start of the search. An empty external archive accepts the current solution. If a new solution is dominated by an individual within the external archive, then such a solution is automatically rejected; otherwise such solution is stored in the external archive. At the end of the search, if the external population has achieved the specified capacity, the adaptive grid procedure is invoked. All the nondominated solutions are stored in external archive. Decision making problem is the process of finding best optimal solution from the existing alternatives. Many methods have been developed to solve Multiple Criteria Decision Making problem (MCDM). A prior knowledge of the relative importance of objectives is required in all MCDM methods.

\section{Problem Formulation}

Figure 2 shows the proposed scheme of multiobjective optimization technique applied to tune the parameters of baseline PI controller. Minimizations of Integral of Absolute Error (IAE) and Maximum Absolute Error (MAE) from nominal values for all outputs at $0 \%$ load condition are chosen as

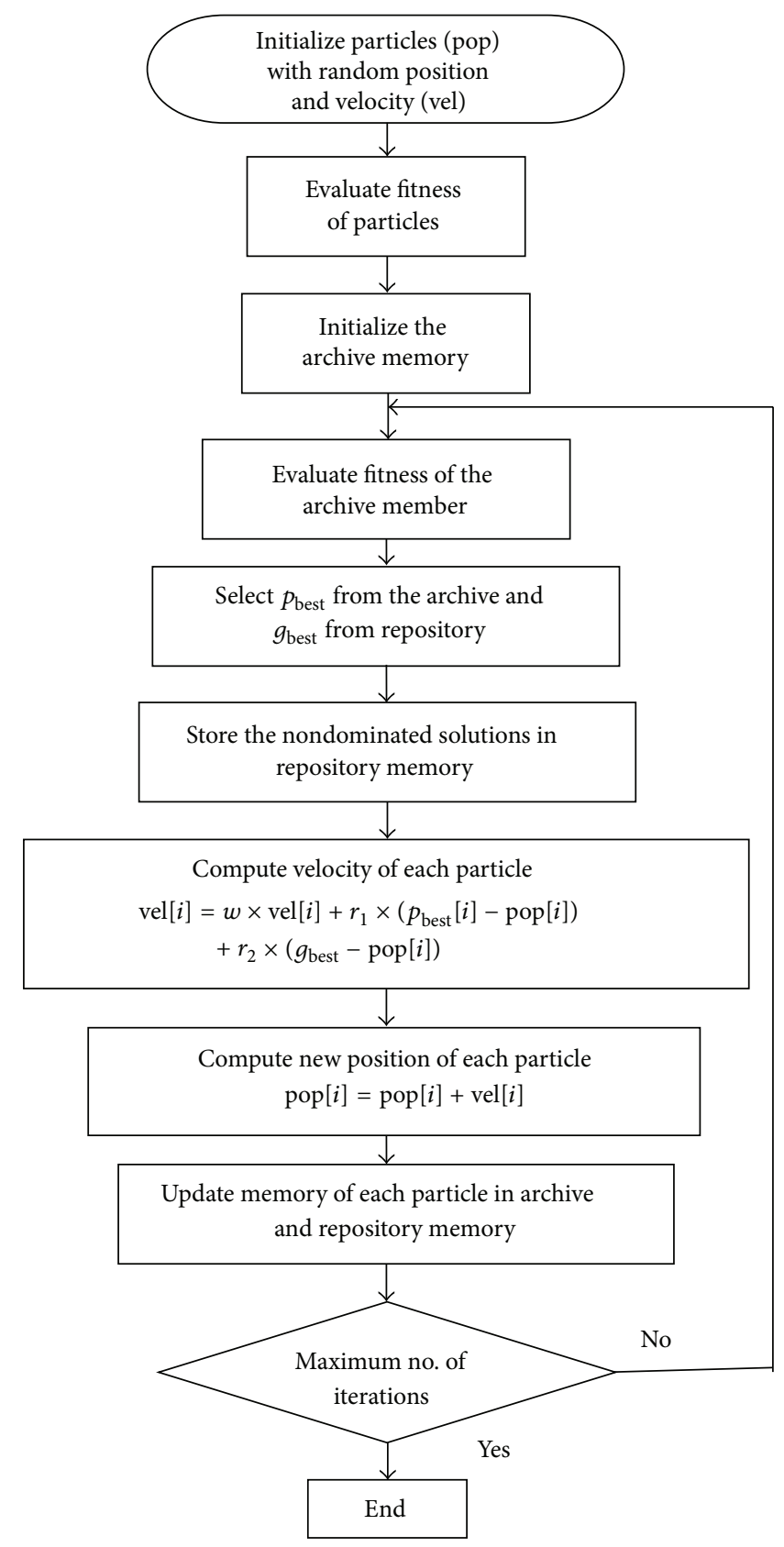

FIGURE 1: Flow chart of Multiobjective Particle Swarm Optimization algorithm.

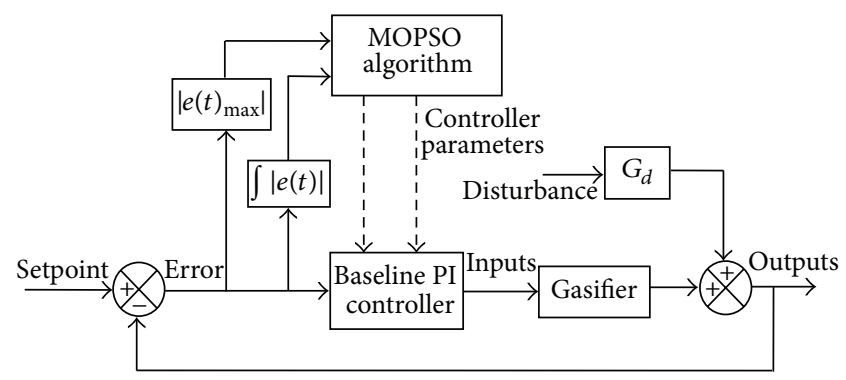

FIGURE 2: Block diagram of optimization scheme. 
TABLE 4: MOPSO tuning objectives.

\begin{tabular}{lc}
\hline Sl. no. & Objectives \\
\hline 1 & MAE of CVGAS over $300 \mathrm{~s}$ \\
2 & MAE of MASS over $300 \mathrm{~s}$ \\
3 & MAE of PGAS over $300 \mathrm{~s}$ \\
4 & MAE of TGAS over $300 \mathrm{~s}$ \\
5 & IAE of CVGAS over $300 \mathrm{~s}$ \\
6 & IAE of MASS over $300 \mathrm{~s}$ \\
7 & IAE of PGAS over $300 \mathrm{~s}$ \\
8 & IAE of TGAS over $300 \mathrm{~s}$ \\
\hline
\end{tabular}

TABLE 5: Controller parameters.

\begin{tabular}{|c|c|c|c|c|c|}
\hline Parameter & Baseline PI & Cuckoo PI & Bat PI & Simm A & MOPSO PI \\
\hline CV_Kp & $-1.226 e-4$ & $-1.226 e-4$ & $-1.226 e-4$ & $-1.5445 e-4$ & $-2.57 e-4$ \\
\hline CV_Ki & $-8.0404 e-5$ & $-8.0404 e-5$ & $-8.0404 e-5$ & $-1.0867 e-4$ & $-7.588 e-4$ \\
\hline BM_Kp & 0.1450706 & 0.1450706 & 0.1450706 & 0.1814 & 0.2465885 \\
\hline BM_Kf & 1.0327973 & 1.0327973 & 1.0327973 & 1.2910 & 1.86302375 \\
\hline $\mathrm{Pr} \_\mathrm{Kp}$ & $2.0189 e-4$ & $3.5427 e-4$ & $4.0149 e-4$ & $2.2281 e-4$ & $2.1424 e-4$ \\
\hline $\mathrm{Pr} \_\mathrm{Ki}$ & $2.6457 e-5$ & $7.0102 e-8$ & $1.14496 e-7$ & $6.14 e-6$ & $1.145 e-5$ \\
\hline Tg_Kp & 1.70129 & 1.70129 & 1.70129 & 2.1266 & 1.76866 \\
\hline Tg_Ki & $9.4794 e-3$ & $9.4794 e-3$ & $9.4794 e-3$ & $1.19 e-2$ & $1.0224 e-2$ \\
\hline
\end{tabular}

objective function for PSO algorithm. Table 4 shows the 8 objective functions chosen for this problem.

Controller parameters of baseline PI controller are taken as decision variables. Input constraints are associated with Simulink model and they are not included in the desired specifications.

Coal gasifier has five manipulated inputs and four outputs. Setpoint to the gasifier is selected in accordance with $0 \%$ operating point. Disturbances such as pressure disturbance, load disturbance, and coal quality disturbance also affect the system performance. For this specific problem, a sinusoidal pressure disturbance of amplitude 0.2 bar and frequency of $0.04 \mathrm{~Hz}$ are applied. The measured outputs are compared with their corresponding setpoint that produces an error signal. MAE and IAE are calculated for $300 \mathrm{sec}$, which acts as the objective function for this optimization algorithm. MOPSO algorithm chooses the parameters of baseline PI controller, which takes necessary control action based on the error signal by manipulating the input variables. The controller should respond quickly enough so that the output variables do not deviate from the setpoint more than the specified constraints. Hence the sampling time is selected as 1 second. This procedure continues until the maximum number of iteration is reached. At the end, MOPSO algorithm provides a set nondominated solution for the controller parameters. From these nondominated solutions, optimal controller parameters are obtained so as to meet the input-output constraints at all load conditions and for all disturbances.

Table 5 shows the controller parameters of baseline-PI, Cuckoo PI, Bat PI, Simm and Liu (denoted as Simm A), and the parameters obtained by the above procedure (denoted by MOPSO-PI).
Cuckoo [24] and Bat algorithm[25] based procedure involved tuning of pressure loop PI controller alone and all the other parameters are similar to baseline controller parameters. A small change in the controller parameter is observed which is sufficient to meet the aforesaid constraints.

\section{Performance Test Results}

Following performance tests are conducted to verify the robustness of the system for the tuned values of baseline PI controller. Test results should satisfy the constraints for all performance tests. Using the tuned parameters, simulation is run for $300 \mathrm{sec}$ at $0 \%, 50 \%$, and $100 \%$ load conditions with sinusoidal and step pressure disturbance.

5.1. Pressure Disturbance Tests. A step change in pressure disturbance of 0.2 bar and a sinusoidal pressure disturbance of amplitude 0.2 bar and frequency $0.04 \mathrm{~Hz}$ are applied to the Alstom gasifier at $0 \%, 50 \%$, and $100 \%$ load conditions.

The dynamic response of Alstom gasifier for step and sinusoidal pressure disturbance at $0 \%, 50 \%$, and $100 \%$ load is shown in Figures 3 and 4, respectively. Figure 3(a) shows the deviation of outputs from nominal values. All outputs meet the performance requirements without violating the output constraints. Since the input limits and rate of change of limits are associated with physical properties of the actuator, inflow is always regulated within the limits.

From Figure 4, it is clear that all the outputs are within the limits. At $0 \%$ load condition, for disturbance rejection performance, steam flow rate reaches its lower limit for sinusoidal pressure disturbance. Performance indices such as MAE and IAE for the above six pressure disturbance tests 

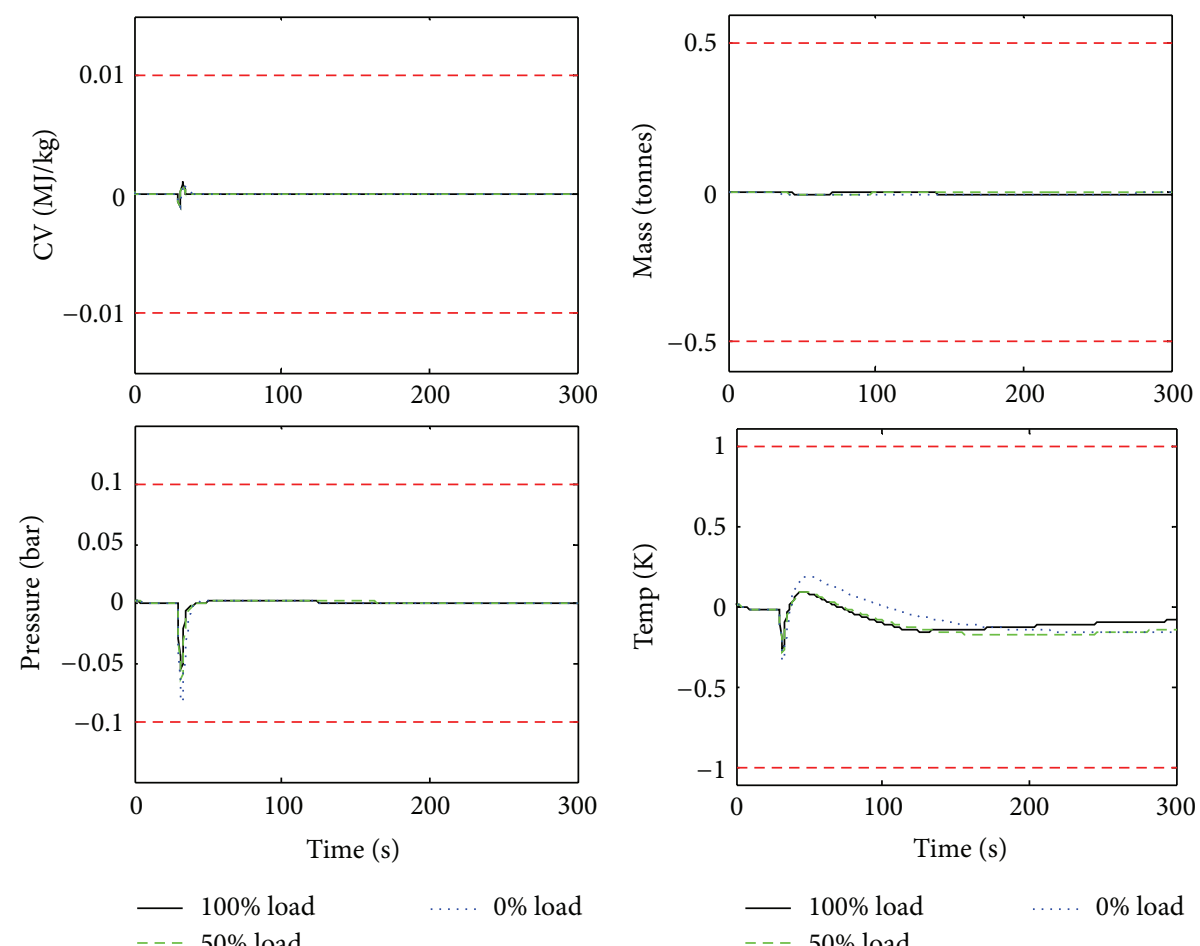

(a) Outputs and limits
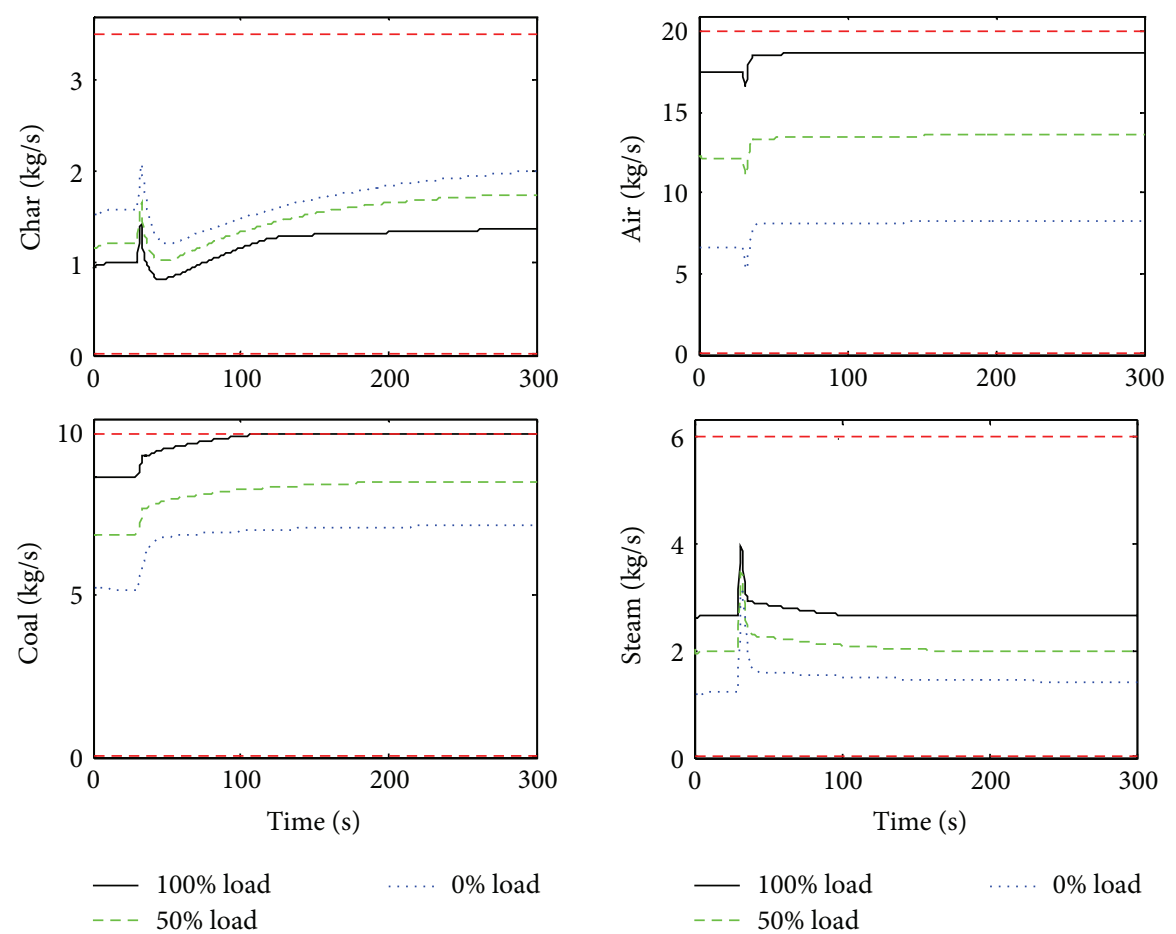

(b) Inputs and limits

Figure 3: Response to step disturbance at $0 \%, 50 \%$, and $100 \%$ load.

are calculated for $300 \mathrm{sec}$ and are listed in Tables 6(a) and $6(b)$.

Table 6(a) shows the comparison of MAE for existing baseline PI controller, Cuckoo PI, Bat PI, Simm A, and
MOPSO-PI controller settings. It was observed that MOPSO based PI controller provides best results for CVGAS and TGAS during sinusoidal and step pressure disturbance. PGAS is well tuned by Cuckoo search and Bat search based PI 

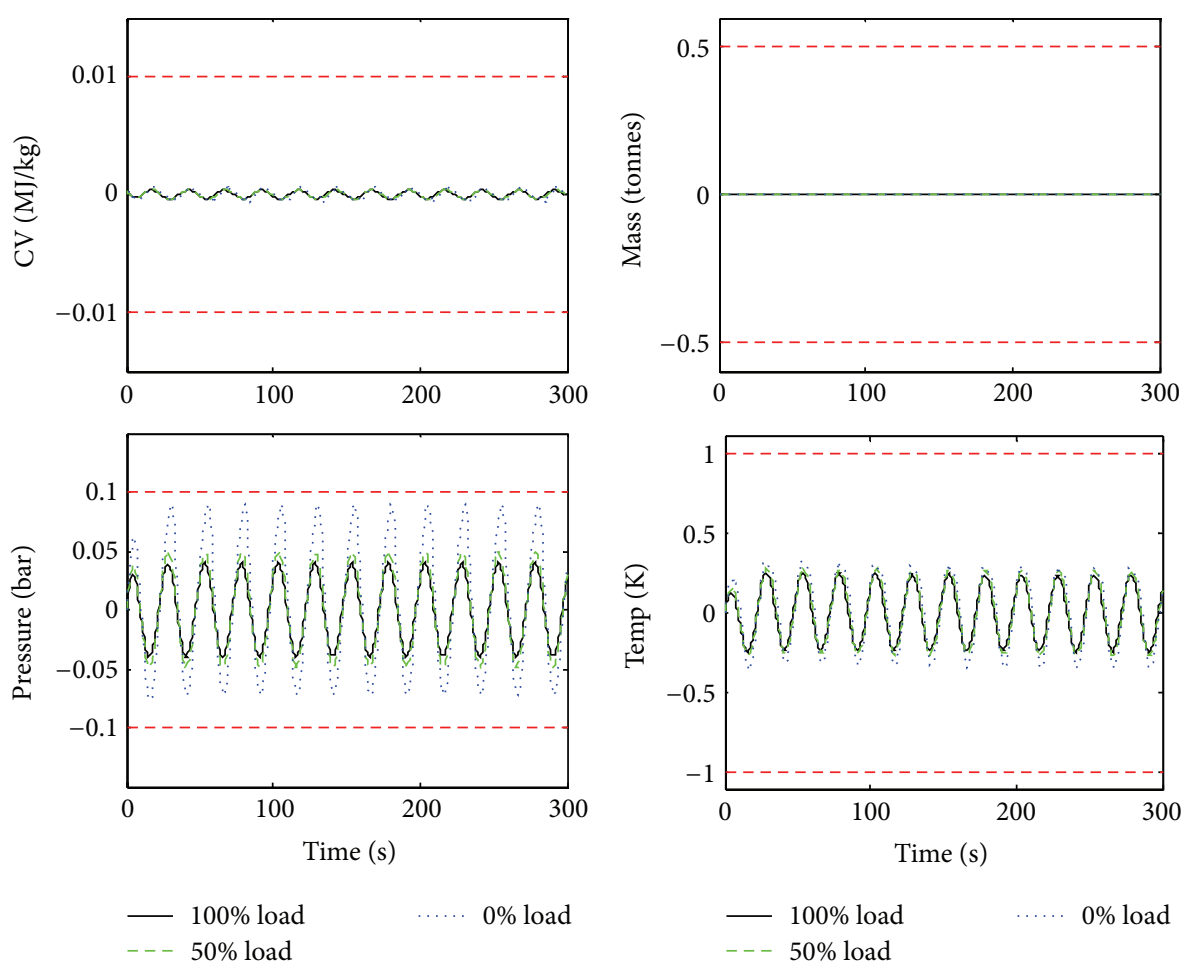

$$
-100 \% \text { load }
$$$$
\text { ..... } 0 \% \text { load }
$$

(a) Outputs and limits
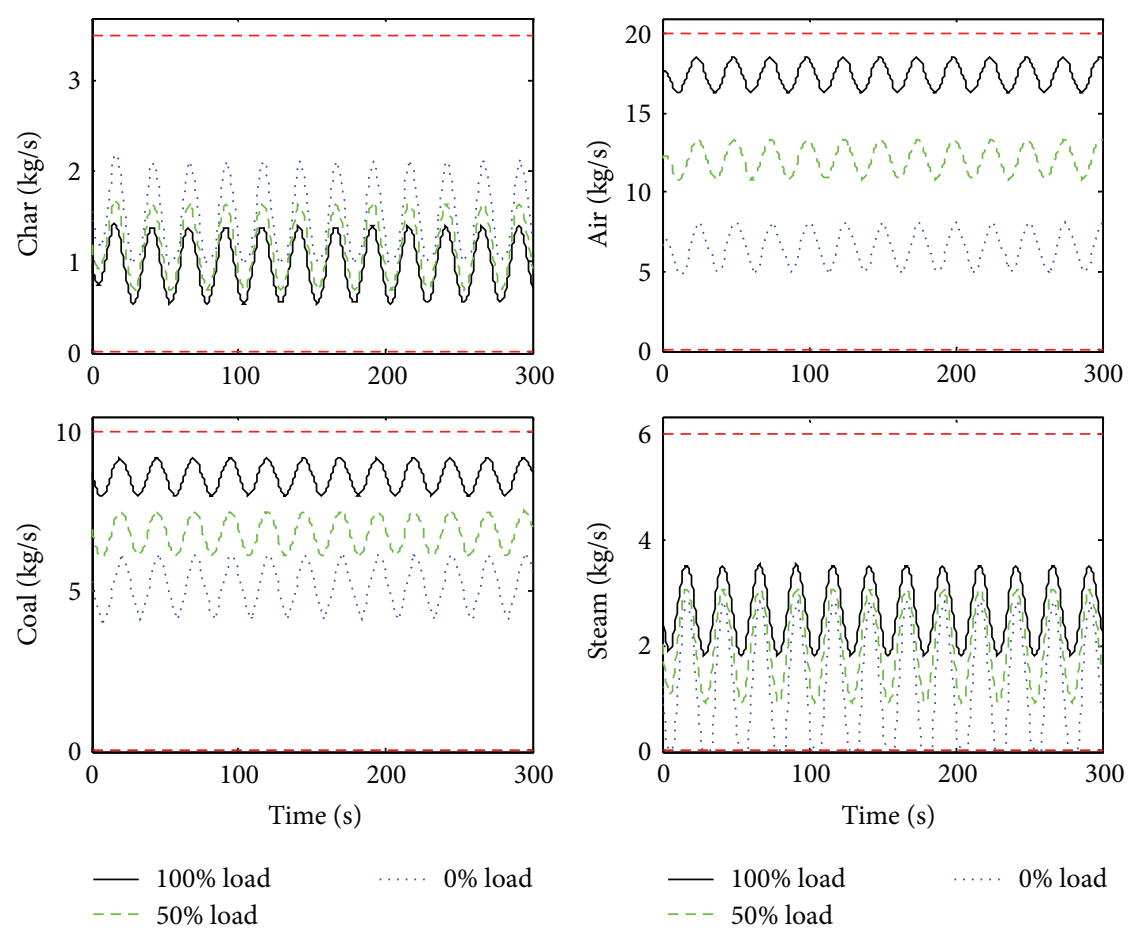

(b) Inputs and limits

Figure 4: Response to sinusoidal disturbance at $0 \%, 50 \%$, and $100 \%$ load.

controllers. A marginal increase in PGAS is observed for sinusoidal and step pressure disturbance with MOPSO-PI controller. At $0 \%$ load, for sinusoidal pressure disturbance, baseline PI controller did not satisfy the constraints (greater than 0.1 bar). It is clear that MOPSO-PI based closed loop system produces better results and meets the performance specifications comfortably even at $0 \%$ load condition. Similarly Table 6(b) shows comparison of IAE indices 
TABLE 6: (a) Summary of test output results-Maximum Absolute Error. (b) Summary of test output results-Integral of Absolute Error.

(a)

\begin{tabular}{|c|c|c|c|c|c|c|}
\hline Test description & Outputs & Baseline PI & Cuckoo PI & Bat PI & Simm A & MOPSO PI \\
\hline \multirow{4}{*}{$100 \%$ load, step disturbance } & CVGAS (KJ/kg) & 4.8533 & 6.0736 & 6.5038 & 4.23649 & 1.0751 \\
\hline & MASS (kg) & 6.9383 & 6.9382 & 6.9382 & 6.9407 & 7.4428 \\
\hline & PGAS (bar) & 0.0499 & 0.040952 & 0.0410 & 0.05131 & 0.0561 \\
\hline & TGAS (K) & 0.2395 & 0.27865 & 0.2941 & 0.22438 & 0.2698 \\
\hline \multirow{4}{*}{$50 \%$ load, step disturbance } & CVGAS (KJ/kg) & 5.0310 & 6.7232 & 7.3247 & 4.45998 & 1.0659 \\
\hline & MASS (kg) & 8.4548 & 8.4548 & 8.4548 & 8.4548 & 9.0476 \\
\hline & PGAS (bar) & 0.0577 & 0.0496 & 0.0494 & 0.05918 & 0.0634 \\
\hline & TGAS (K) & 0.2660 & 0.31869 & 0.3395 & 0.24766 & 0.2852 \\
\hline \multirow{4}{*}{$0 \%$ load, step disturbance } & CVGAS (KJ/kg) & 5.8914 & 8.0184 & 9.8772 & 4.70603 & 1.0445 \\
\hline & MASS (kg) & 11.053 & 11.053 & 11.053 & 11.0529 & 11.8115 \\
\hline & PGAS (bar) & 0.0772 & 0.075986 & 0.0760 & 0.078547 & 0.0829 \\
\hline & TGAS (K) & 0.3232 & 0.40339 & 0.4315 & 0.30182 & 0.3218 \\
\hline \multirow{4}{*}{$100 \%$ load, sinusoidal disturbance } & CVGAS (KJ/kg) & 4.1025 & 3.7562 & 3.7838 & 2.4006 & 0.3603 \\
\hline & MASS (kg) & 10.858 & 10.756 & 10.799 & 10.173 & 9.9925 \\
\hline & PGAS (bar) & 0.0496 & 0.029062 & 0.0258 & 0.04049 & 0.0401 \\
\hline & TGAS (K) & 0.3784 & 0.35226 & 0.3566 & 0.280606 & 0.2491 \\
\hline \multirow{4}{*}{$50 \%$ load, sinusoidal disturbance } & CVGAS (KJ/kg) & 4.7122 & 4.3039 & 4.3730 & 2.7118 & 0.4094 \\
\hline & MASS (kg) & 12.852 & 12.719 & 12.783 & 11.991 & 11.7817 \\
\hline & PGAS (bar) & 0.0623 & 0.036325 & 0.0325 & 0.04949 & 0.0495 \\
\hline & TGAS (K) & 0.4226 & 0.39123 & 0.3982 & 0.31069 & 0.2785 \\
\hline \multirow{4}{*}{$0 \%$ load, sinusoidal disturbance } & CVGAS (KJ/kg) & 5.8585 & 6.8594 & 7.9930 & 3.4857 & 0.7028 \\
\hline & MASS (kg) & 16.346 & 16.296 & 16.365 & 15.532 & 15.2117 \\
\hline & PGAS (bar) & 0.1196 & 0.099138 & 0.0991 & 0.09041 & 0.0879 \\
\hline & TGAS (K) & 0.4791 & 0.51445 & 0.5699 & 0.36566 & 0.3573 \\
\hline & & (b) & & & & \\
\hline Test description & Outputs & Baseline PI & Cuckoo PI & Bat PI & Simm A & MOPSO PI \\
\hline \multirow{4}{*}{$100 \%$ load, step disturbance } & CVGAS (KJ/kg) & 30.492 & 34.956 & 37.035 & 21.4567 & 4.1192 \\
\hline & MASS (kg) & 795.29 & 766.03 & 768.72 & 770.167 & 845.6540 \\
\hline & PGAS (bar) & 0.3883 & 0.71104 & 0.6365 & 0.66801 & 0.4134 \\
\hline & TGAS (K) & 32.449 & 31.668 & 31.812 & 25.3313 & 28.0122 \\
\hline \multirow{4}{*}{$50 \%$ load, step disturbance } & CVGAS (KJ/kg) & 32.224 & 37.329 & 38.920 & 23.588 & 4.3242 \\
\hline & MASS (kg) & 421.53 & 442.03 & 437.36 & 905.62 & 1671.89 \\
\hline & PGAS (bar) & 0.4669 & 0.96041 & 0.8552 & 0.8308 & 0.51978 \\
\hline & TGAS (K) & 38.433 & 37.073 & 37.278 & 31.295 & 35.5484 \\
\hline \multirow{4}{*}{$0 \%$ load, step disturbance } & CVGAS (KJ/kg) & 43.864 & 46.585 & 49.858 & 30.7476 & 5.65885 \\
\hline & MASS (kg) & 667.9 & 573.95 & 580.91 & 834.466 & 1754.91 \\
\hline & PGAS (bar) & 0.59493 & 2.2373 & 1.9707 & 0.86776 & 0.56538 \\
\hline & TGAS (K) & 38.388 & 35.714 & 36.169 & 29.5588 & 32.109 \\
\hline \multirow{4}{*}{$100 \%$ load, sinusoidal disturbance } & CVGAS (KJ/kg) & 773.94 & 703.34 & 709.01 & 450.358 & 68.077 \\
\hline & MASS (kg) & 2076.5 & 2075 & 2073.8 & 2073.03 & 2191.29 \\
\hline & PGAS (bar) & 9.2825 & 5.4295 & 4.8282 & 7.4122 & 7.452 \\
\hline & TGAS (K) & 66.998 & 62.211 & 62.933 & 49.092 & 44.986 \\
\hline \multirow{4}{*}{$50 \%$ load, sinusoidal disturbance } & CVGAS (KJ/kg) & 879.66 & 802.54 & 812.64 & 506.179 & 76.7957 \\
\hline & MASS (kg) & 2522.2 & 2517.3 & 2515.5 & 2515.83 & 2655.36 \\
\hline & PGAS (bar) & 11.506 & 6.7252 & 6.0099 & 9.125 & 9.1915 \\
\hline & TGAS (K) & 74.717 & 69.129 & 70.358 & 54.105 & 50.16 \\
\hline \multirow{4}{*}{$0 \%$ load, sinusoidal disturbance } & CVGAS (KJ/kg) & 1039.5 & 1061.7 & 1126.2 & 640.636 & 97.1409 \\
\hline & MASS (kg) & 3007.2 & 3040.6 & 3018.1 & 3156.57 & 3336.64 \\
\hline & PGAS (bar) & 19.145 & 13.123 & 12.702 & 14.4267 & 14.723 \\
\hline & TGAS (K) & 79.541 & 82.098 & 85.674 & 64.371 & 60.749 \\
\hline
\end{tabular}



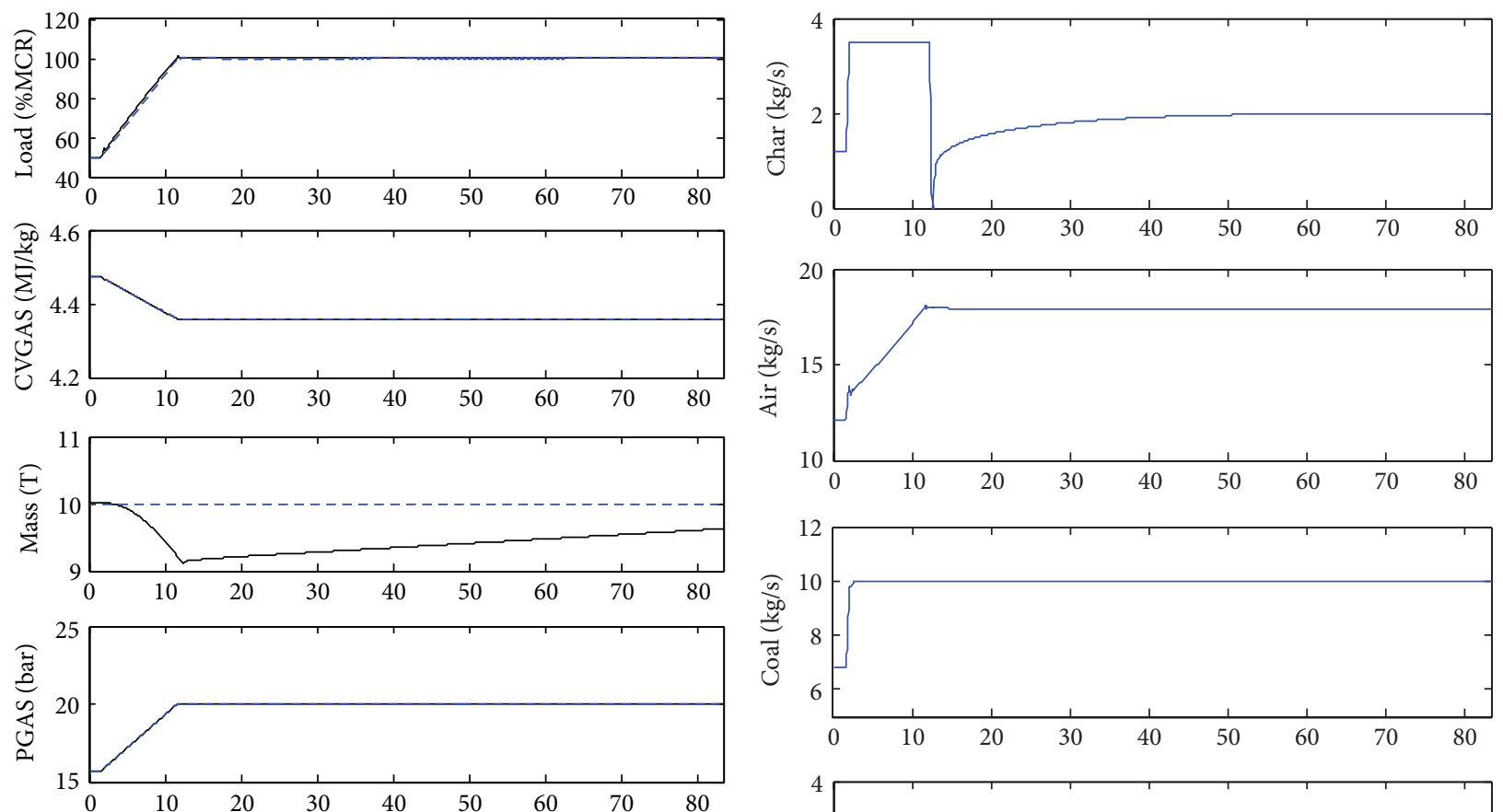

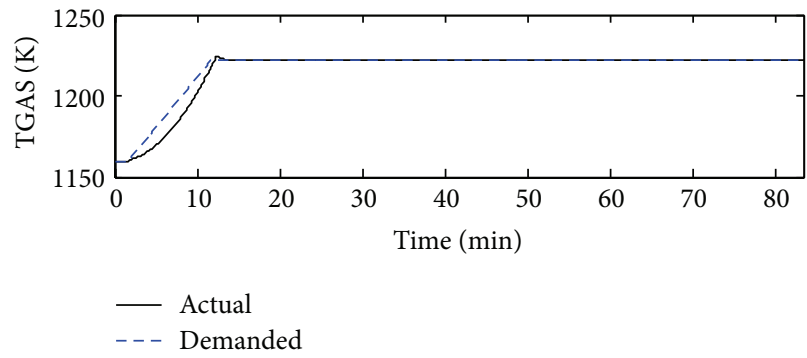

(a) Response to ramped increase in load

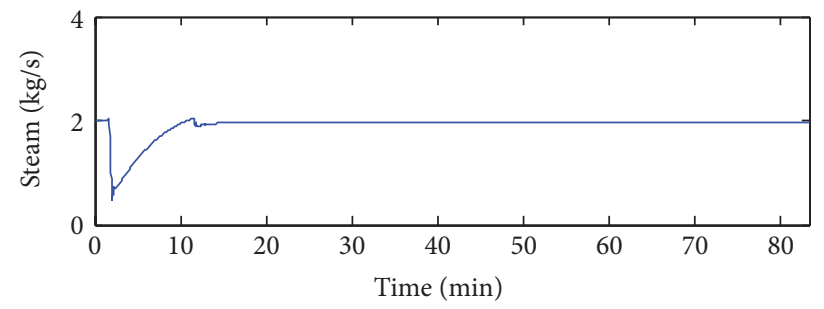

(b) Input response to load change

FIgURE 5: Response to load increase from $50 \%$ to $100 \%$ load.

for the aforesaid controllers. For step pressure disturbance CVGAS, PGAS, and TGAS are well tuned by MOPSOPI, Bat and Cuckoo PI, and Simm A, respectively. For sinusoidal pressure disturbance CVGAS and TGAS are well tuned by MOPSO-PI while PGAS is well tuned by Bat PI controller.

Performance indices show that the tuned MOPSO based PI controller provides better results and meets all the performance requirements without violating the constraints.

5.2. Load Change Test. Stability of coal gasifier and controller function across the working range of the plant $(0 \%, 50 \%$, and $100 \%$ load) is investigated. The system is started at $50 \%$ load, allowed to reach the steady state, then ramped it to $100 \%$ over a period of 600 seconds (5\% per min). The response is shown in Figure 5. Actual load, CVGAS, and PGAS track their demands quickly to setpoint while Mass takes more time to reach its steady state, though manipulated inputs coal flow and char flow have reached their steady state immediately. TGAS reached its steady state at around
13 minutes from the start, immediately char flow rate is regulated towards its steady state point, and MASS begins to return to its setpoint, as the coal flow rate reached its maximum.

This procedure is repeated for $0 \%$ to $50 \%$ change in load. Similar type of response is obtained. It is clear from the results that MOPSO-PI controller is able to track the changes in load.

5.3. Coal Variation (Model Error) Test. The quality of syngas depends on various factors such as type of coal (calorific value of coal) and moisture content. Quality of coal greatly affects each output of the gasifier. In this test, the quality of coal that is fed to gasifier is increased and decreased by $18 \%$; input-output responses for sinusoidal and step change in pressure disturbance are tabulated at $100 \%, 50 \%$, and $0 \%$ load conditions.

For sinusoidal change in pressure disturbance, at $0 \%$ load, for $-18 \%$ change in coal quality, PGAS reaches its upper limit. For the same pressure disturbance, at 100\% load TGAS reaches it upper and lower limits for $+18 \%$ and $-18 \%$ change 

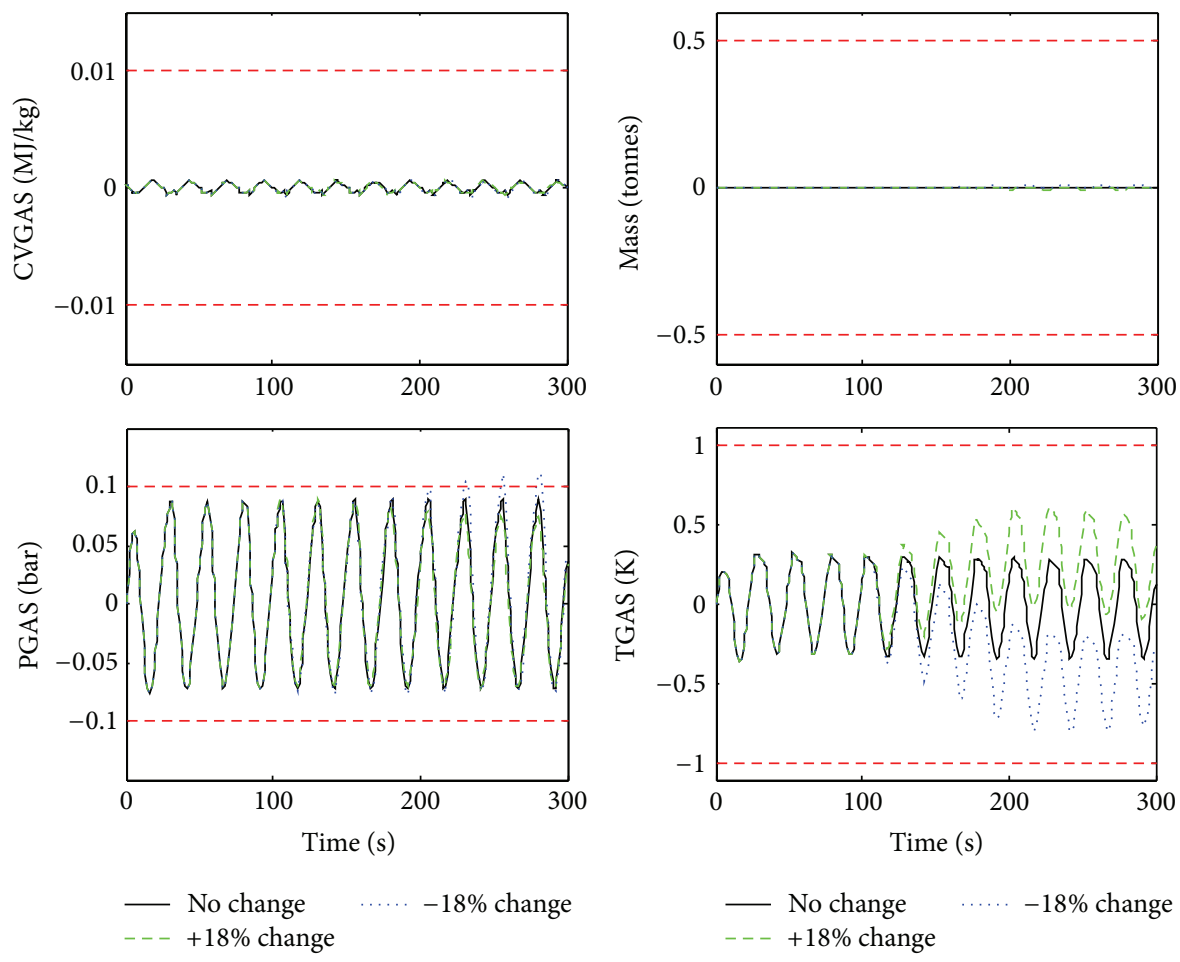

(a) Outputs and limits
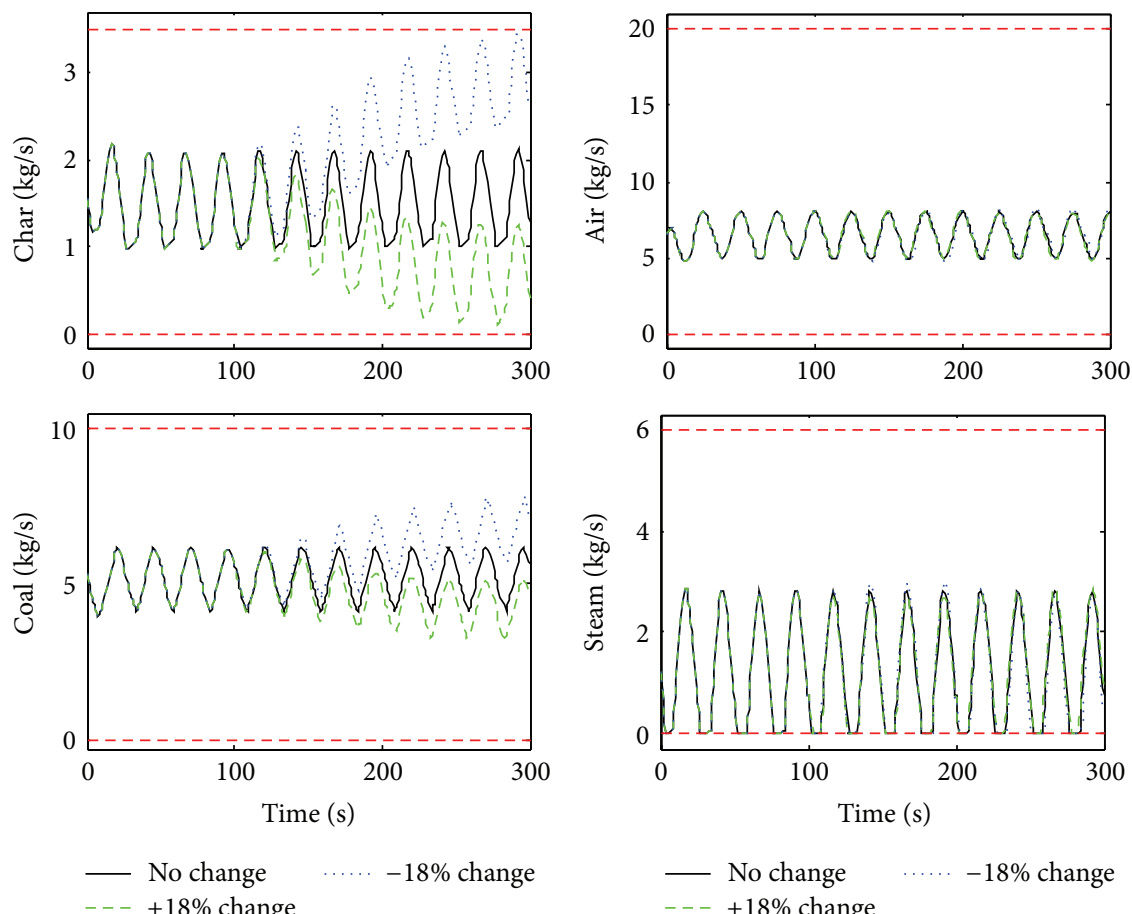

(b) Inputs and limits

Figure 6: Response to sinusoidal disturbance at $0 \%$ load.

in coal quality, respectively. For the other entire scenario the outputs meet the performance requirements without violating the constraints. Figures 6,7 , and 8 show the response of gasifier at $0 \%, 50 \%$, and $100 \%$ load condition for $\pm 18 \%$ coal quality variations and for sinusoidal change in pressure disturbance.

This procedure was repeated for step change in pressure disturbance along with coal quality variations. Figures 9, 

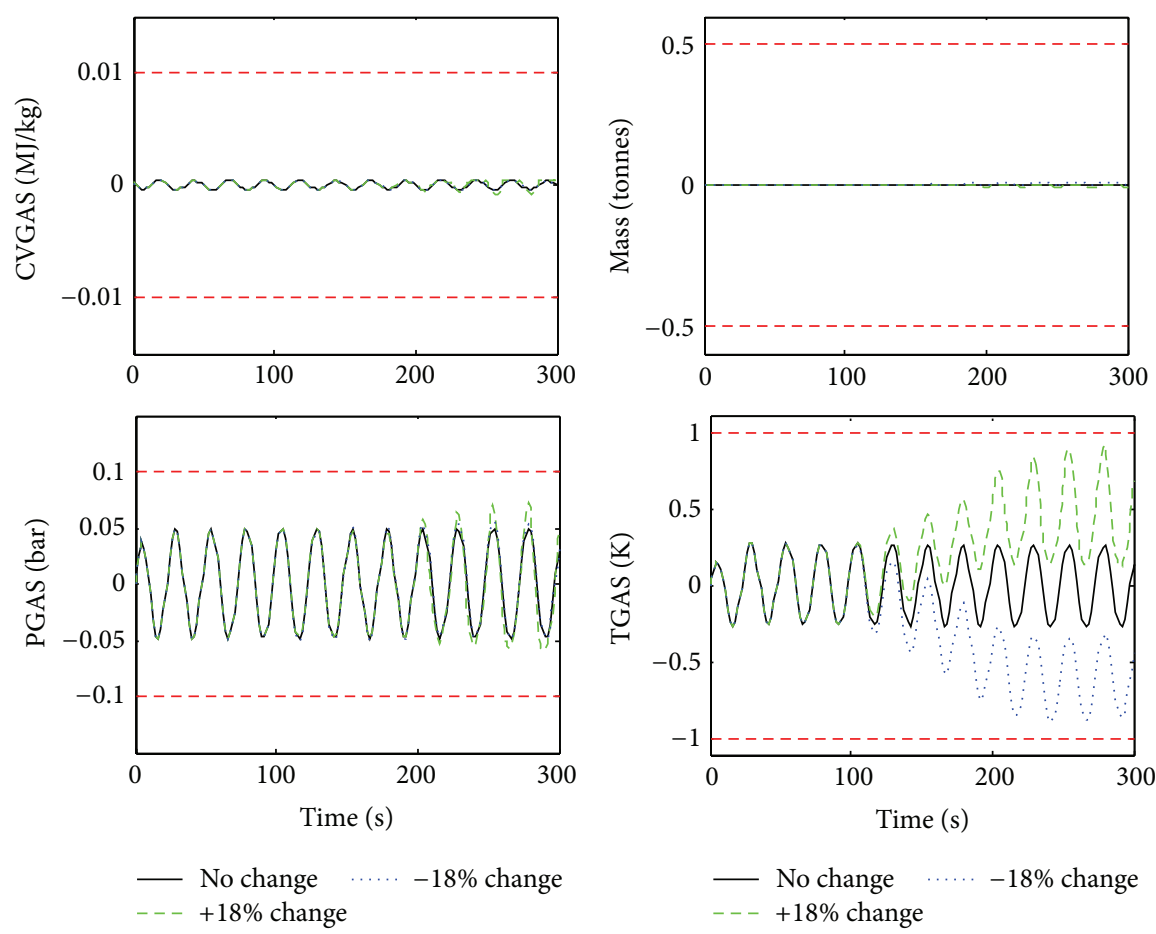

(a) Outputs and limits
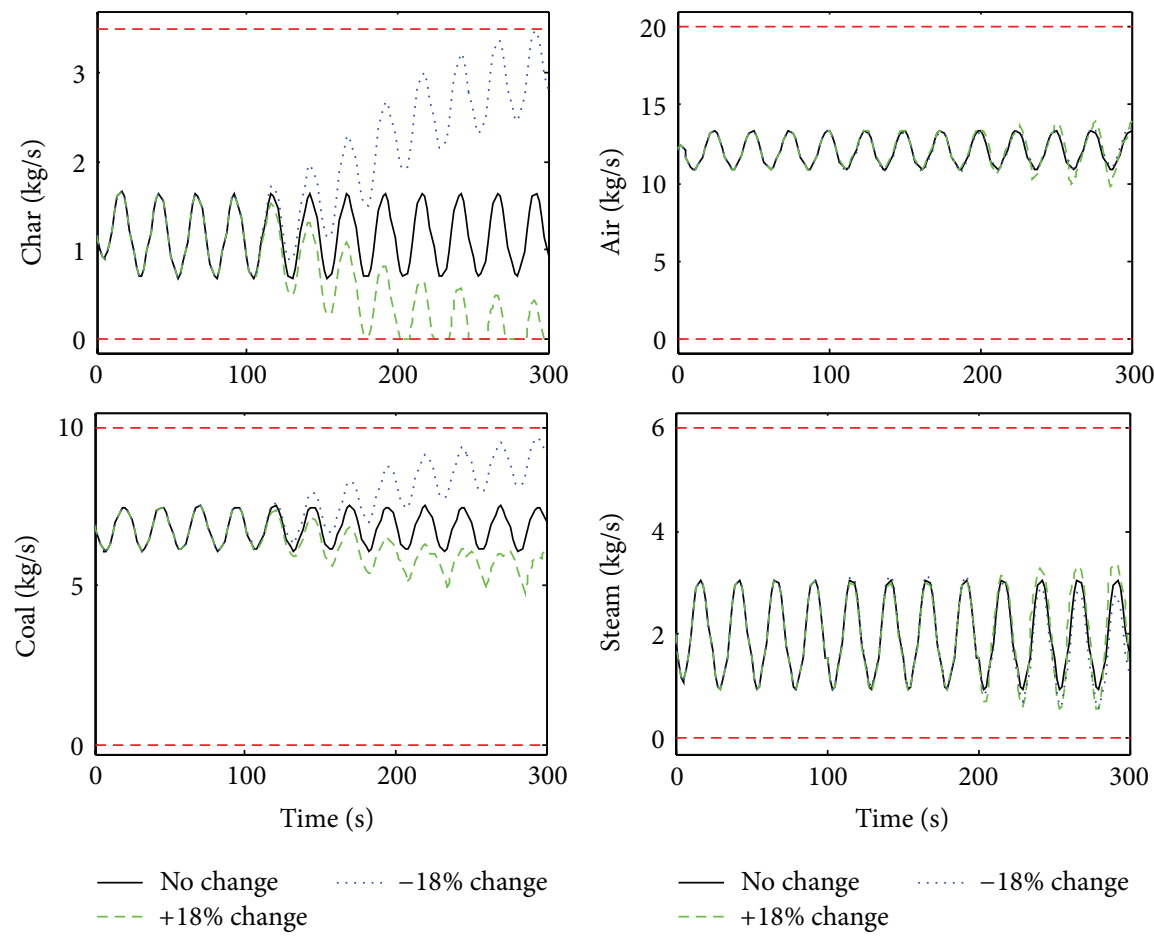

(b) Inputs and limits

Figure 7: Response to sinusoidal disturbance at $50 \%$ load.

10 , and 11 show the response of gasifier at $0 \%, 50 \%$, and $100 \%$ load condition for $\pm 18 \%$ coal quality variations and for step change in pressure disturbance. For step change in pressure disturbance, all the outputs meet the performance requirements without violating the constraints at $0 \%, 50 \%$, and $100 \%$ load conditions for $+18 \%$ and $-18 \%$ change in coal quality variations.

Table 7 shows the violation variables under decreasing $(-18 \%)$ and increasing $(+18 \%)$ coal quality variations during sinusoidal and step change in pressure disturbance. 

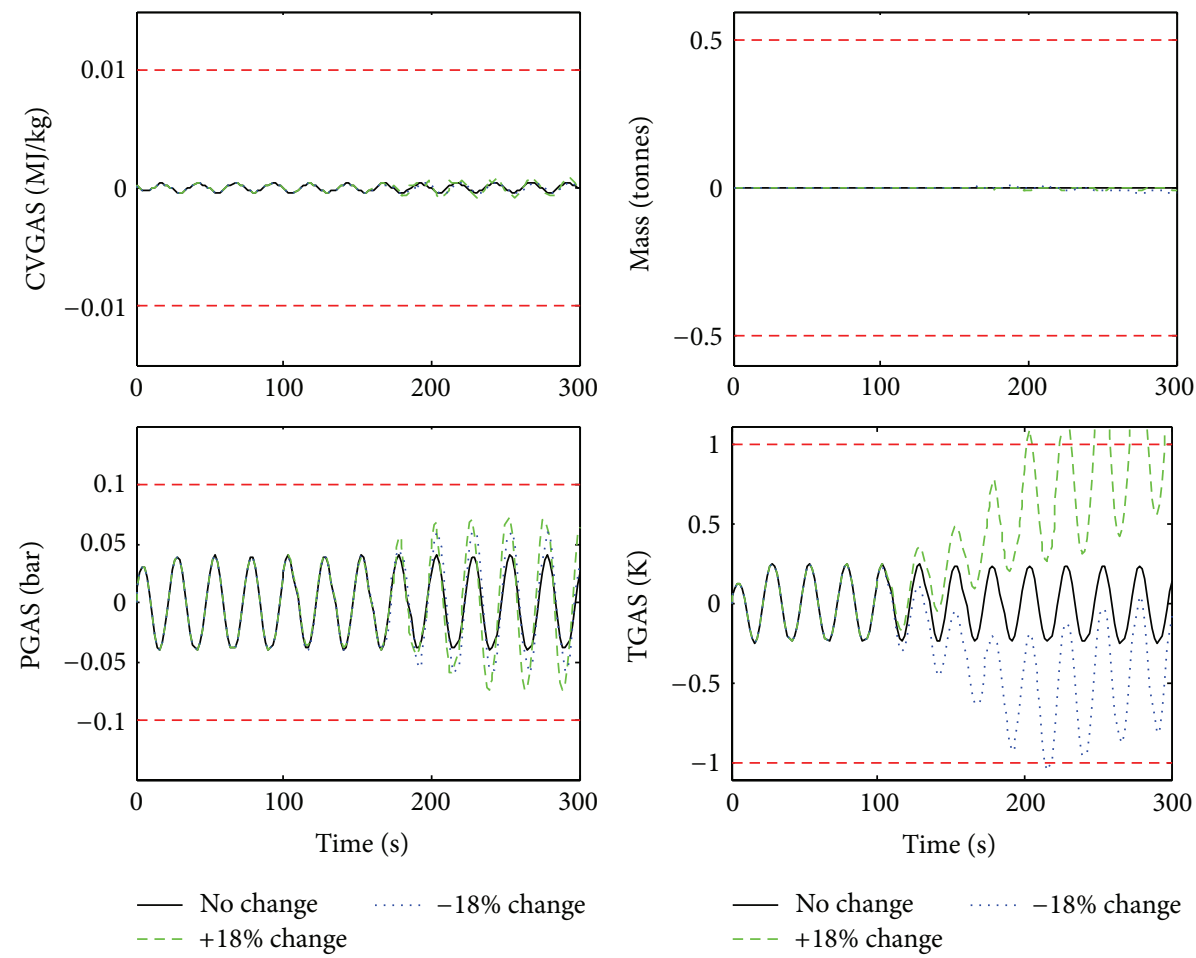

(a) Outputs and limits
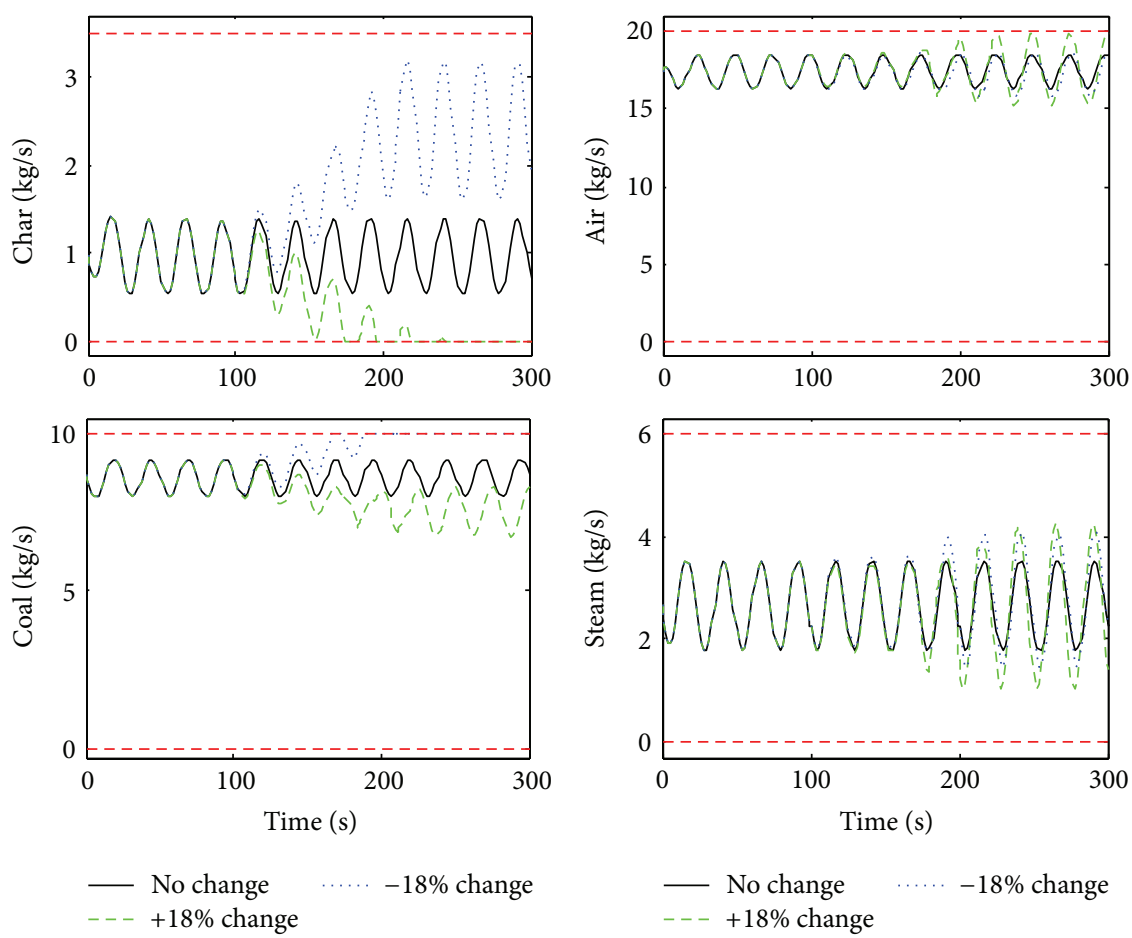

(b) Inputs and limits

FIgURE 8: Response to sinusoidal disturbance at 100\% load.

Table 8 shows allowed increase and decrease scope of coal quality for each scenario. Baseline PI controller did not satisfy the constraints even for the desired coal quality (calorific value) during $0 \%$ load under sinusoidal pressure disturbance.
It is seen that MOPSO based baseline PI controller provides better response for wide range of coal quality variations as compared to the existing methods $[11,17,23-$ $25,28]$. 

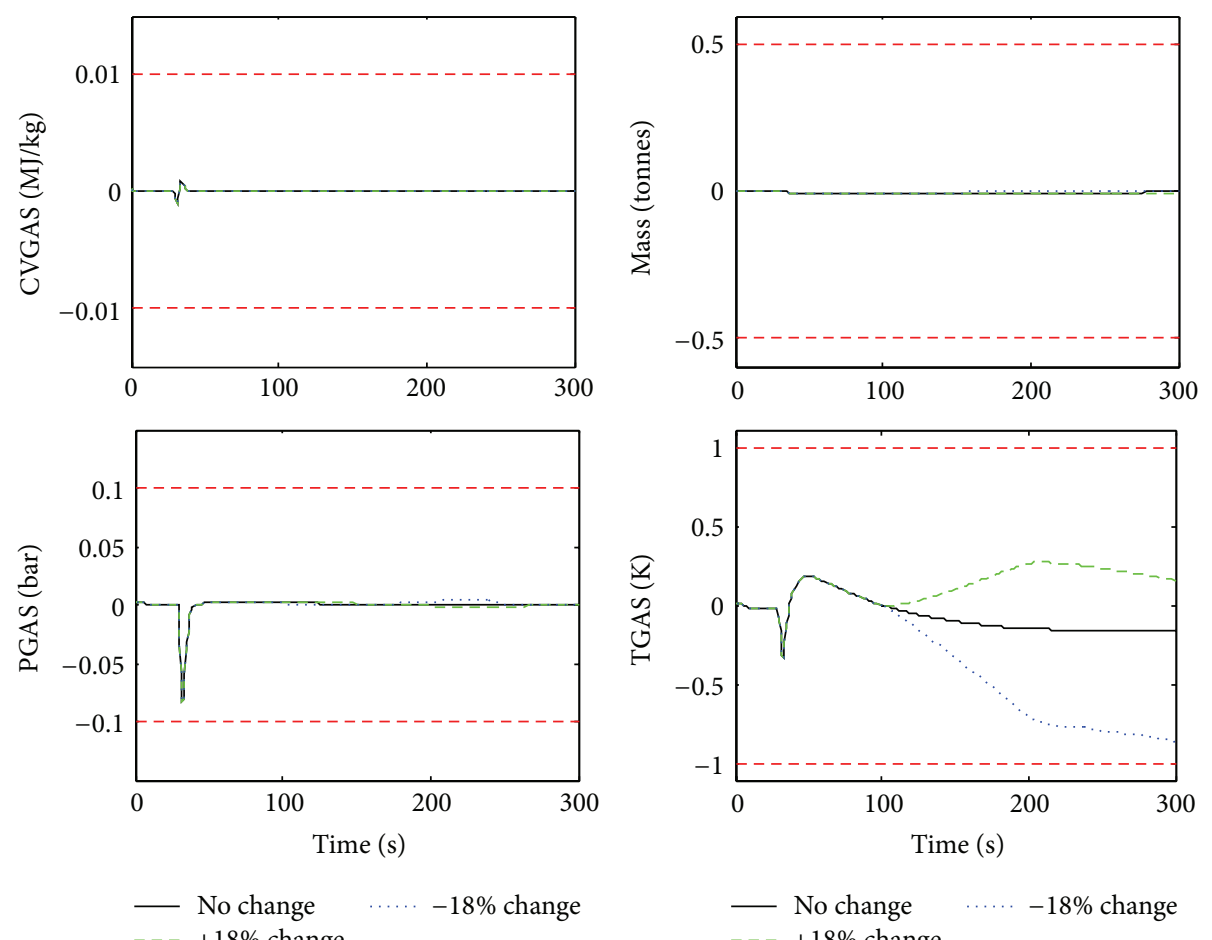

(a) Outputs and limits
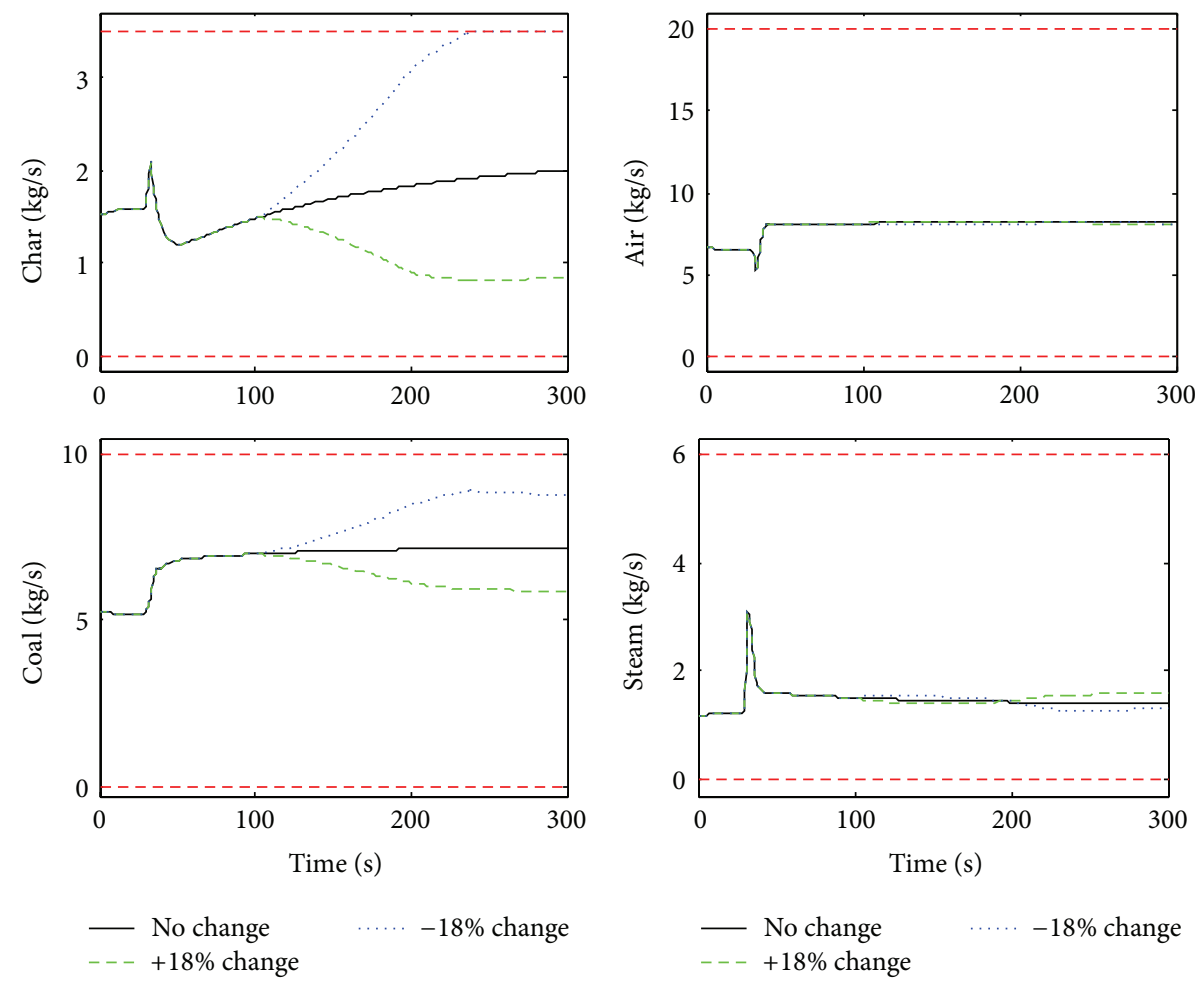

(b) Inputs and limits

Figure 9: Response to step disturbance at $0 \%$ load. 

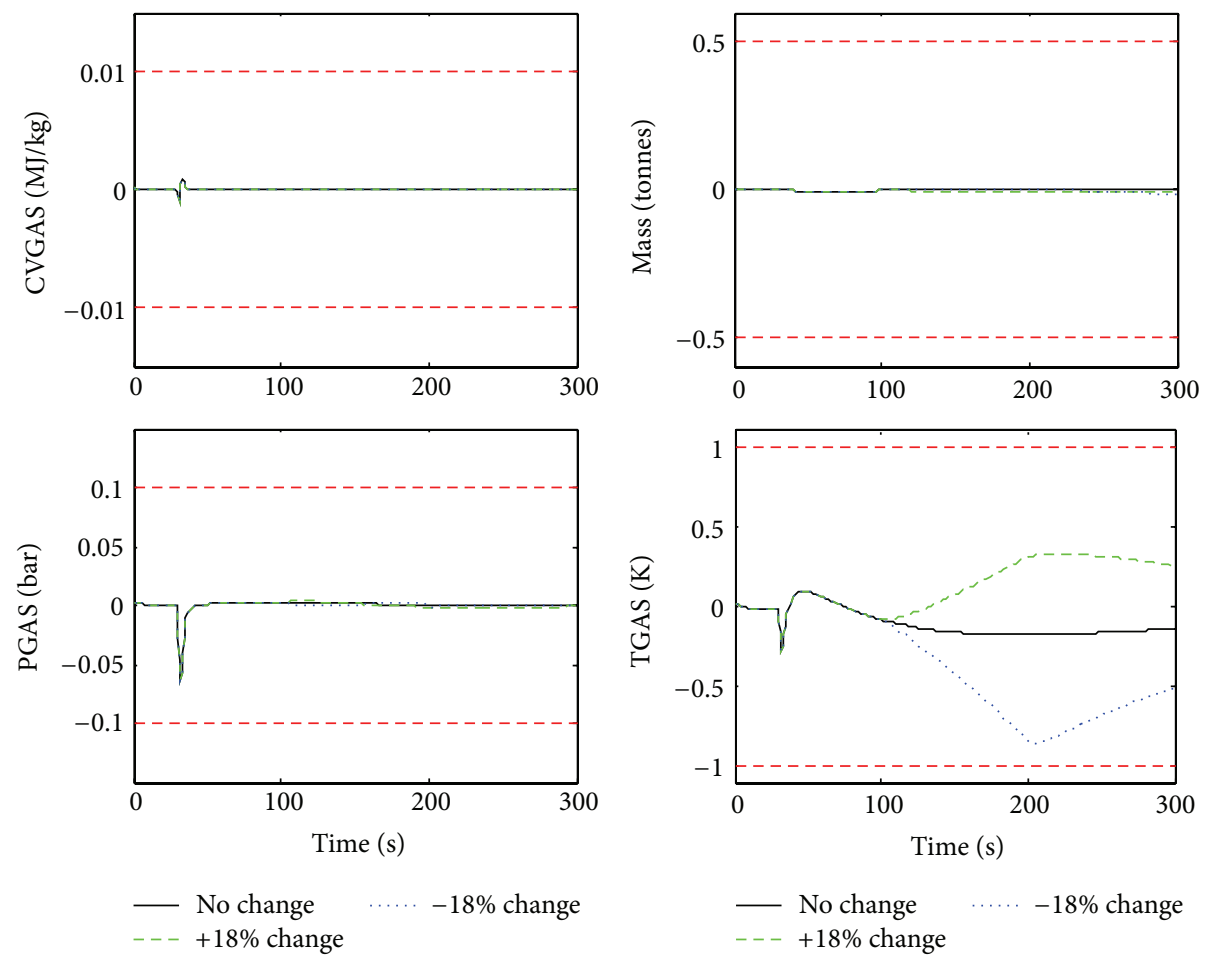

(a) Outputs and limits
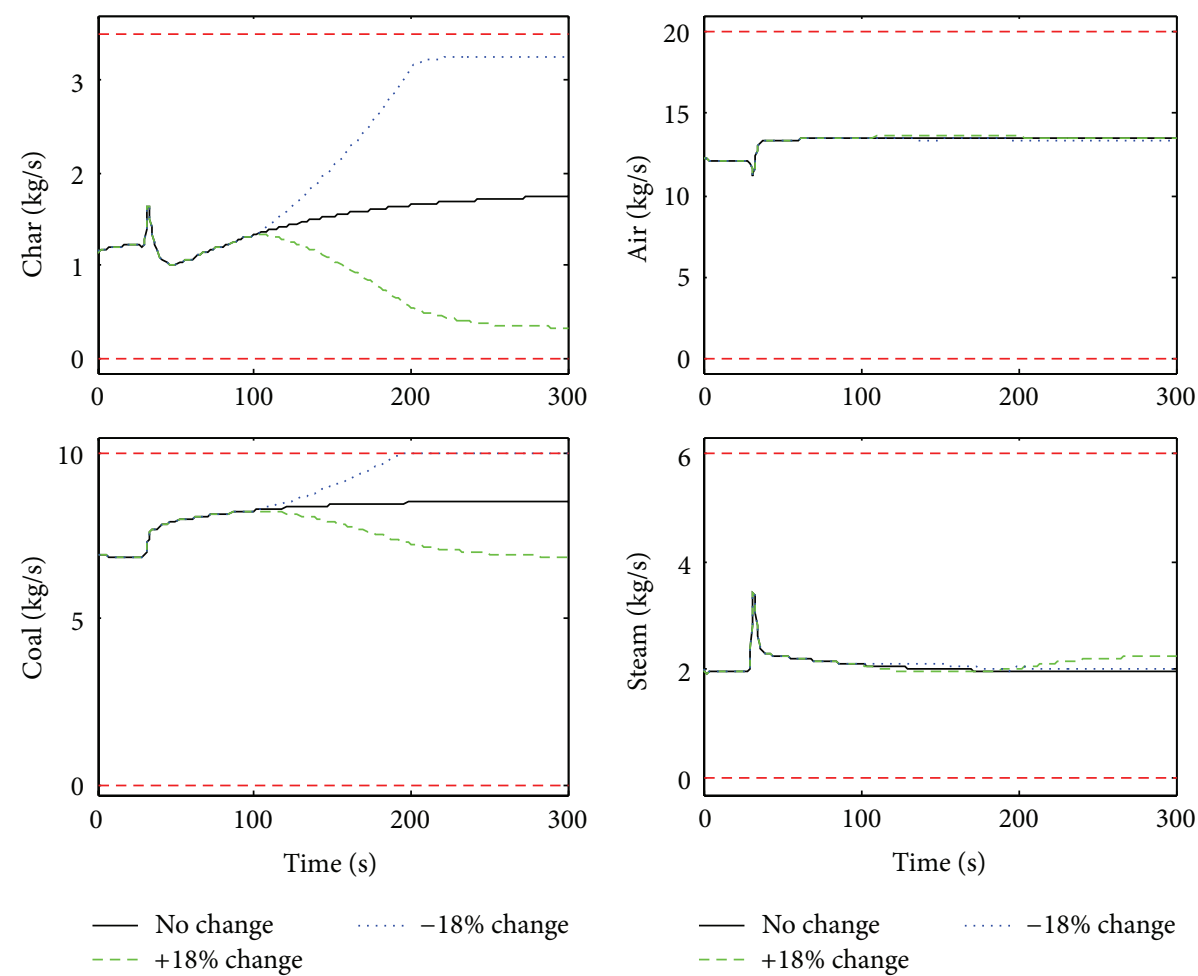

(b) Inputs and limits

Figure 10: Response to step disturbance at 50\% load. 

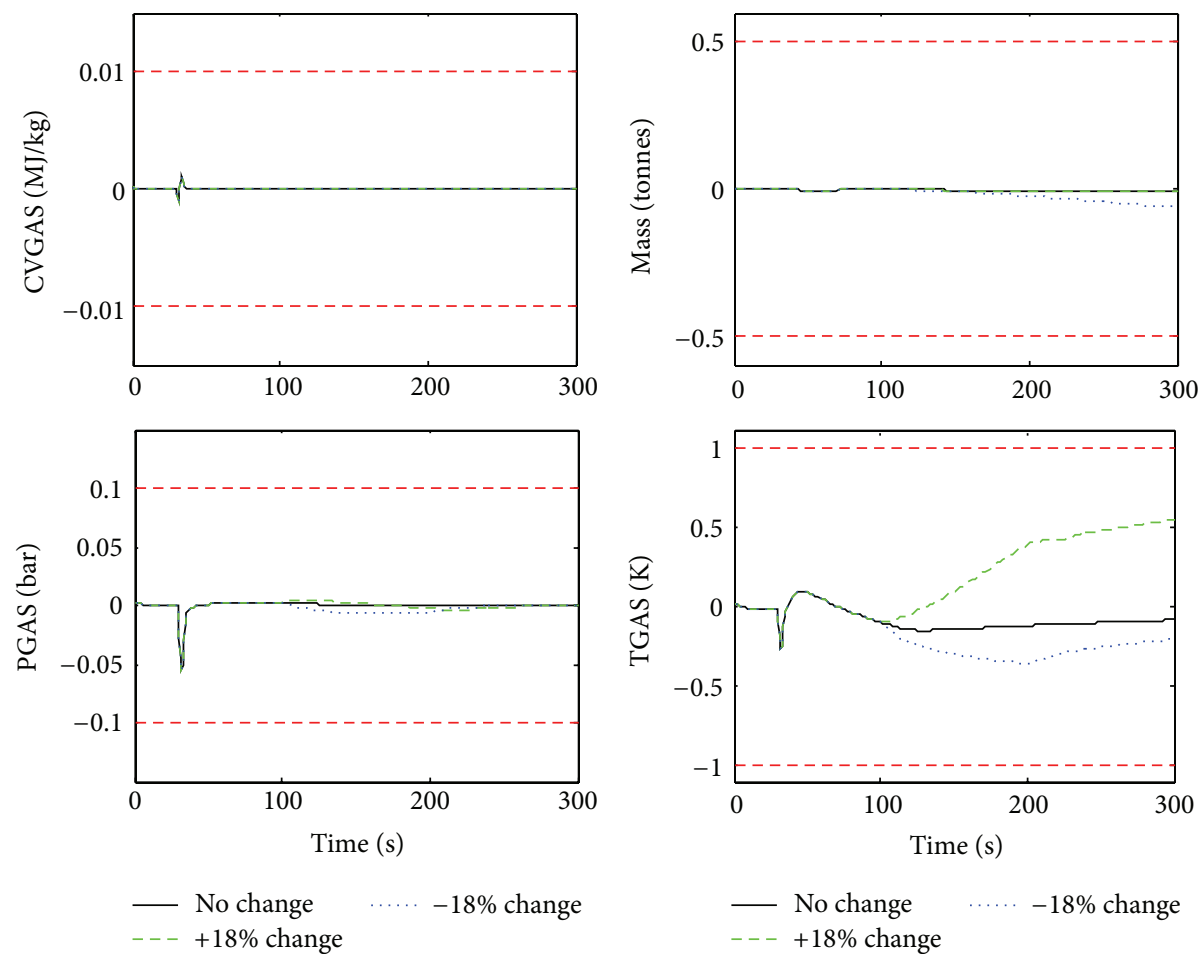

(a) Outputs and Limits
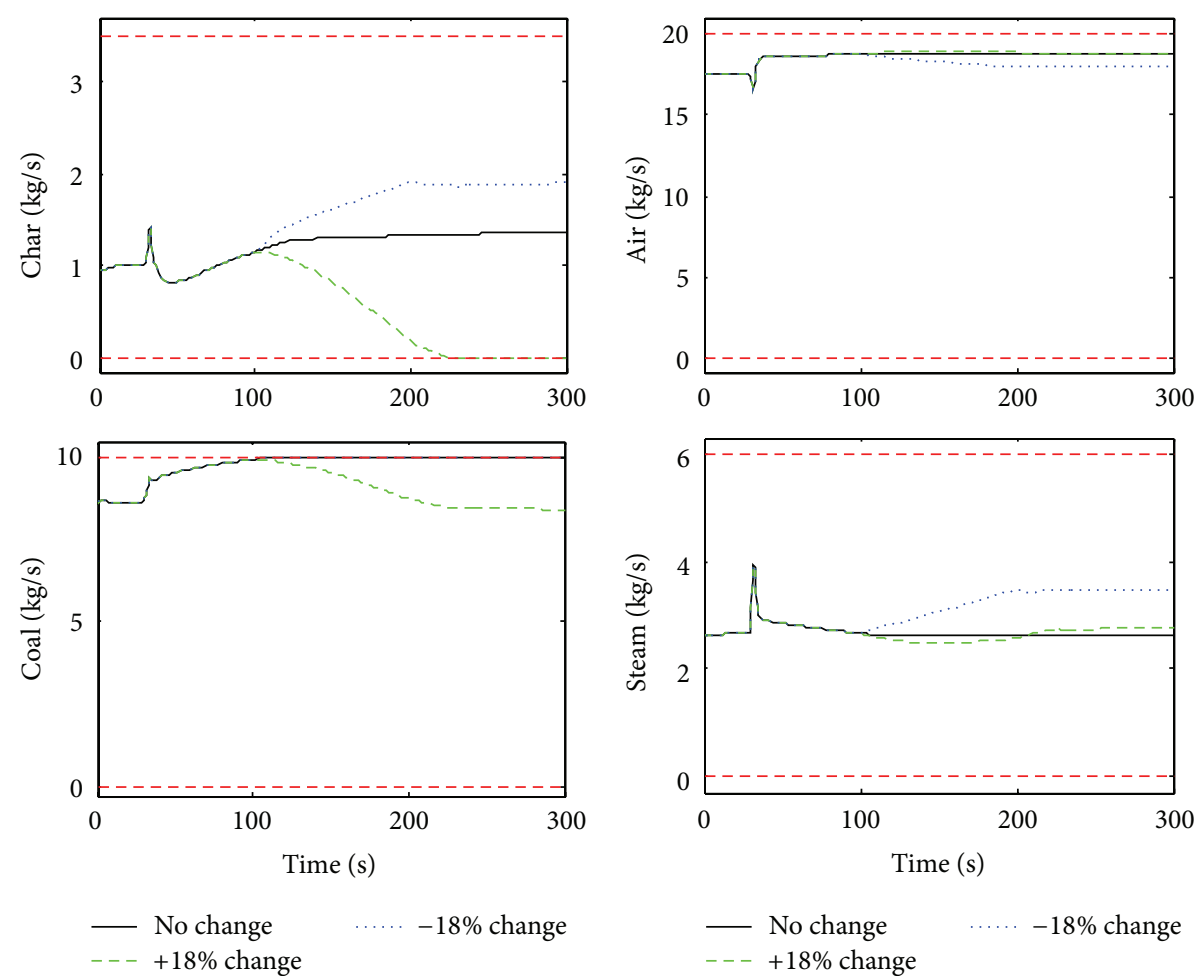

(b) Inputs and Limits

FIGURE 11: Response to step disturbance at $100 \%$ load. 
TABLE 7: Violation variables under coal quality change $( \pm 18 \%)$ ( $\uparrow$ : the variable reaches its upper limit; $\downarrow$ : the variable reaches its lower limit).

\begin{tabular}{|c|c|c|c|c|c|c|}
\hline Load & & & & & & \\
\hline Disturbance type & Sine & Step & Sine & Step & Sine & Step \\
\hline $\begin{array}{l}\text { Coal quality } \\
\text { increase }(+18 \%) \\
\end{array}$ & $\begin{array}{l}\text { Char } \downarrow \\
\text { T gas } \uparrow\end{array}$ & Char $\downarrow$ & Char $\downarrow$ & $\begin{array}{l}\text { Within } \\
\text { limits }\end{array}$ & WStm $\downarrow$ & $\begin{array}{l}\text { Within } \\
\text { limits }\end{array}$ \\
\hline $\begin{array}{l}\text { Coal quality } \\
\text { decrease }(-18 \%)\end{array}$ & $\begin{array}{l}\text { Coal } \uparrow \\
\text { T gas } \downarrow\end{array}$ & Coal $\uparrow$ & $\begin{array}{l}\text { Within } \\
\text { limits }\end{array}$ & Coal $\uparrow$ & $\begin{array}{c}\text { Pgas } \uparrow \\
\text { WStm } \downarrow\end{array}$ & Char $\uparrow$ \\
\hline
\end{tabular}

TABLE 8: Comparison of allowed coal quality variation (\%).

\begin{tabular}{|c|c|c|c|c|c|c|}
\hline \multirow{2}{*}{$\begin{array}{l}\text { Load } \\
\text { Disturbance }\end{array}$} & \multicolumn{2}{|c|}{$100 \%$} & \multicolumn{2}{|c|}{$50 \%$} & \multicolumn{2}{|c|}{$0 \%$} \\
\hline & Sine & Step & Sine & Step & Sine & Step \\
\hline Baseline PI [11] & $(-14,11)$ & $(-18,18)$ & $(-18,16)$ & $(-18,18)$ & $(0,0)$ & $(-18,18)$ \\
\hline Simm A [22] & $(-13,8)$ & $(-5,14)$ & $(-14,14)$ & $(-12,18)$ & $(0,5)$ & $(-8,18)$ \\
\hline MOPI [23] & $(-13,8)$ & $(-5,14)$ & $(-14,14)$ & $(-12,18)$ & $(-3,18)$ & $(-8,18)$ \\
\hline SOPI [23] & $(-13,8)$ & $(-6,13)$ & $(-14,14)$ & $(-12,18)$ & $(-4,18)$ & $(-8,18)$ \\
\hline Cuckoo PI [24] & $(-15,12)$ & $(-18,18)$ & $(-18,17)$ & $(-18,18)$ & $(0,6)$ & $(-18,18)$ \\
\hline Bat PI [25] & $(-15,12)$ & $(-18,18)$ & $(-18,17)$ & $(-18,18)$ & $(0,7)$ & $(-18,18)$ \\
\hline Optimal PI [28] & $(-17,13)$ & $(-18,18)$ & $(-18,18)$ & $(-18,18)$ & $(-7,18)$ & $(-18,18)$ \\
\hline PADRC [17] & $(-18,6)$ & $(-17,14)$ & $(-18,10)$ & $(-12,18)$ & $(-18,18)$ & $(-8,18)$ \\
\hline MOPSO PI & $(-16,13)$ & $(-18,18)$ & $(-18,18)$ & $(-18,18)$ & $(-9,18)$ & $(-18,18)$ \\
\hline
\end{tabular}

\section{Conclusion}

In this paper a Multiobjective Particle Swarm Optimization (MOPSO) algorithm is proposed to fine-tune the parameters of baseline PI controller of Alstom gasifier benchmark challenge II. MOPSO algorithm provides set of nondominated solutions for the baseline PI controller, among which a suitable set of PI parameters are selected. The performance tests such as pressure disturbance, load change, and coal quality variations are investigated. During pressure disturbance test, the controller with optimized settings meets all the performance requirements at $0 \%, 50 \%$, and $100 \%$ load conditions. Load change test shows good results. During coal quality test, the gasifier along with optimized controller settings verifies its capability to handle wide range of coal quality variations.

\section{Conflict of Interests}

The authors declare that there is no conflict of interests regarding the publication of this paper.

\section{Acknowledgment}

The authors would like to thank Dr. Roger Dixon, Director of Systems Engineering Doctorate Centre and Head of Control Systems Group, Loughborough University, UK, for useful communication through email, and the managements of St. Joseph's College of Engineering, Chennai and Sri Krishna College of Engineering \& Technology, Coimbatore for providing necessary assistance to complete the research work.

\section{References}

[1] R. Dixon, A. W. Pike, and M. S. Donne, "The ALSTOM benchmark challenge on gasifier control," Journal of Systems and Control Engineering, vol. 214, no. 6, pp. 389-394, 2000.

[2] B. N. Asmar, W. E. Jones, and J. A. Wilson, "A process engineering approach to the ALSTOM gasifier problem," Journal of Systems and Control Engineering, vol. 214, no. 6, pp. 441-452, 2000.

[3] E. Prempain, I. Postlethwaite, and X. D. Sun, "Robust control of the gasifier using a mixed-sensitivity $\mathrm{H}_{\infty}$ approach," Journal of Systems and Control Engineering, vol. 214, no. 6, pp. 415-426, 2000.

[4] N. Munro, J. M. Edmunds, E. Kontogiannis, and S. T. Impram, "A sequential loop closing approach to the ALSTOM gasifier problem," Journal of Systems and Control Engineering, vol. 214, no. 6, pp. 427-439, 2000.

[5] M. J. Rice, J. A. Rossiter, and J. Schuurmans, "An advanced predictive control approach to the ALSTOM gasifier problem," Journal of Systems and Control Engineering, vol. 214, no. 6, pp. 405-412, 2000.

[6] I. A. Griffin, P. Schroder, A. J. Chipperfield, and P. J. Fleming, "Multi-objective optimization approach to the ALSTOM gasifier problem," Journal of Systems and Control Engineering, vol. 214, no. 6, pp. 453-468, 2000.

[7] G. P. Liu, R. Dixon, and S. Daley, "Multi-objective optimaltuning proportional-integral controller design for the ALSTOM gasifier problem," Journal of Systems and Control Engineering, vol. 214, no. 6, pp. 395-404, 2000.

[8] C. J. Taylor, A. P. McCabe, P. C. Young, and A. Chotai, "Proportional-integral-plus (PIP) control of the ALSTOM gasifier problem," Journal of Systems and Control Engineering, vol. 214 , no. 6, pp. 469-480, 2000. 
[9] R. Dixon, "Alstom Benchmark Challenge II: Control of a nonlinear gasifier model," ALSTOM, 2002, http://www.iee.org/ OnComms/PN/controlauto/Specification_v2.pdf.

[10] R. Dixon, "Benchmark challenge at control 2004 [control system design]," IEE Computing and Control Engineering, vol. 15, no. 6, pp. 21-23, 2004.

[11] R. Dixon and A. W. Pike, "Alstom benchmark challenge II on gasifier control," IEE Proceedings: Control Theory and Applications, vol. 153, no. 3, pp. 254-261, 2006.

[12] L. Sivakumar and X. Anitha Mary, "A reduced order transfer function models for alstom gasifier using genetic algorithm," International Journal of Computer Applications, vol. 46, no. 5, pp. 31-38, 2012.

[13] R. Kotteeswaran and L. Sivakumar, "Lower order transfer function identification of nonlinear MIMO system-Alstom gasifier," International Journal of Engineering Research and Applications, vol. 2, no. 4, pp. 1220-1226, 2012.

[14] C. J. Taylor and E. M. Shaban, "Multivariable proportionalintegral-plus (PIP) control of the ALSTOM nonlinear gasifier simulation," IEE Proceedings: Control Theory and Applications, vol. 153, no. 3, pp. 277-285, 2006.

[15] R. K. Al Seyab, Y. Cao, and S. H. Yang, "Predictive control for the ALSTOM gasifier problem," IEE Proceedings: Control Theory and Applications, vol. 153, no. 3, pp. 293-301, 2006.

[16] R. Agustriyanto and J. Zhang, "GRDG analysis of the ALSTOM gasifier benchmark process under model plant mismatch," in Proceedings of the International Conference on Control, Automation and Systems (ICCAS '07), pp. 883-888, October 2007.

[17] W. Tan, G. Lou, and L. Liang, "Partially decentralized control for ALSTOM gasifier," ISA Transactions, vol. 50, no. 3, pp. 397-408, 2011.

[18] C. S. Chin and N. Munro, "Control of the ALSTOM gasifier benchmark problem using $\mathrm{H}_{2}$ methodology," Journal of Process Control, vol. 13, no. 8, pp. 759-768, 2003.

[19] J. A. Wilson, M. Chew, and W. E. Jones, "A state estimation based approach to gasifier control," in Proceedings of the Control Conference, University of Bath, Bath, UK, 2004.

[20] A. Nobakhti and H. Wang, "A simple self-adaptive Differential Evolution algorithm with application on the ALSTOM gasifier," Applied Soft Computing, vol. 8, no. 1, pp. 350-370, 2008.

[21] R. Agustriyanto and J. Zhang, "Control structure selection for the ALSTOM gasifier benchmark process using GRDG analysis," International Journal of Modelling, Identification and Control, vol. 6, no. 2, pp. 126-135, 2009.

[22] A. Simm and G. P. Liu, "Improving the performance of the ALSTOM baseline controller using multiobjective optimisation," IEE Proceedings: Control Theory and Applications, vol. 153, no. 3, pp. 286-292, 2006.

[23] Y. Xue, D. Li, and F. Gao, "Multi-objective optimization and selection for the PI control of ALSTOM gasifier problem," Control Engineering Practice, vol. 18, no. 1, pp. 67-76, 2010.

[24] L. Sivakumar and R. Kotteeswaran, "Soft computing based partial-retuning of decentralised PI controller of nonlinear multivariable process," in ICT and Critical Infrastructure: Proceedings of the 48th Annual Convention of Computer Society of India-Vol 1, vol. 248 of Advances in Intelligent Systems and Computing, pp. 117-124, Springer, Allschwil, Switzerland, 2014.

[25] R. Kotteeswaran and L. Sivakumar, "A Novel Bat algorithm based re-tuning of PI controller of coal gasifier for optimum response," in Mining Intelligence and Knowledge Exploration, vol. 8284 of Lecture Notes in Computer Science, pp. 506-517, Springer, Allschwil, Switzerland, 2013.
[26] R. Kotteeswaran and L. Sivakumar, "Optimal partial-retuning of decentralised PI controller of coal gasifier using Bat Algorithm," in Swarm, Evolutionary, and Memetic Computing, vol. 8297 of Lecture Notes in Computer Science, pp. 750-761, Springer, Allschwil, Switzerland, 2013.

[27] R. Kotteeswaran and L. Sivakumar, "Normalized normal constraint algorithm based multi-objective optimal tuning of decentralised PI controller of nonlinear multivariable processcoal gasifier," in Swarm, Evolutionary, and Memetic Computing, vol. 8297 of Lecture Notes in Computer Science, pp. 333-344, Springer, Allschwil, Switzerland, 2013.

[28] R. Kotteeswaran and L. Sivakumar, "Performance evaluation of optimal PI controller for ALSTOM gasifier during coal quality variations," Journal of Process Control, vol. 24, no. 1, pp. 27-36, 2014.

[29] C. M. Fonseca and P. J. Fleming, "An overview of evolutionary algorithms in multi-objective optimization," Evolutionary Computation, vol. 3, no. 1, pp. 1-16, 1995.

[30] K. Deb, A. Pratap, S. Agarwal, and T. Meyarivan, "A fast and elitist multiobjective genetic algorithm: NSGA-II," IEEE Transactions on Evolutionary Computation, vol. 6, no. 2, pp. 182-197, 2002.

[31] J. D. Knowles and D. W. Corne, "Approximating the nondominated front using the Pareto Archived Evolution Strategy," Evolutionary Computation, vol. 8, no. 2, pp. 149-172, 2000.

[32] C. C. A. Coello and G. T. Pulido, "Multiobjective optimization using a micro-genetic algorithm," in Proceedings of the Genetic and Evolutionary Computation Conference (GECCO '01), pp. 274-282, San Francisco, Calif, USA, 2001.

[33] J. Kennedy, R. C. Eberhart, and Y. Shi, Swarm Intelligence, Morgan Kaufmann, San Francisco, Calif, USA, 2001.

[34] V. Rajinikanth and K. Latha, "Tuning and retuning of PID controller for unstable systems using evolutionary algorithm," ISRN Chemical Engineering, vol. 2012, Article ID 693545, 11 pages, 2012.

[35] K. Latha, V. Rajinikanth, and P. M. Surekha, "PSO-based PID controller design for a class of stable and unstable systems," ISRN Artificial Intelligence, vol. 2013, Article ID 543607, 11 pages, 2013.

[36] C. A. C. Coello, G. T. Pulido, and M. S. Lechuga, "Handling multiple objectives with particle swarm optimization," IEEE Transactions on Evolutionary Computation, vol. 8, no. 3, pp. 256-279, 2004. 

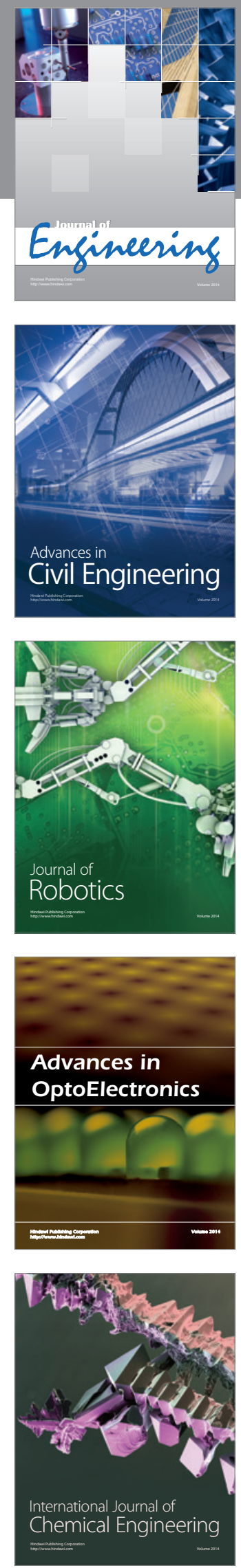

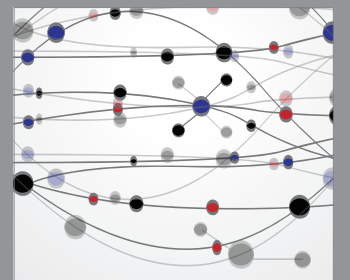

The Scientific World Journal
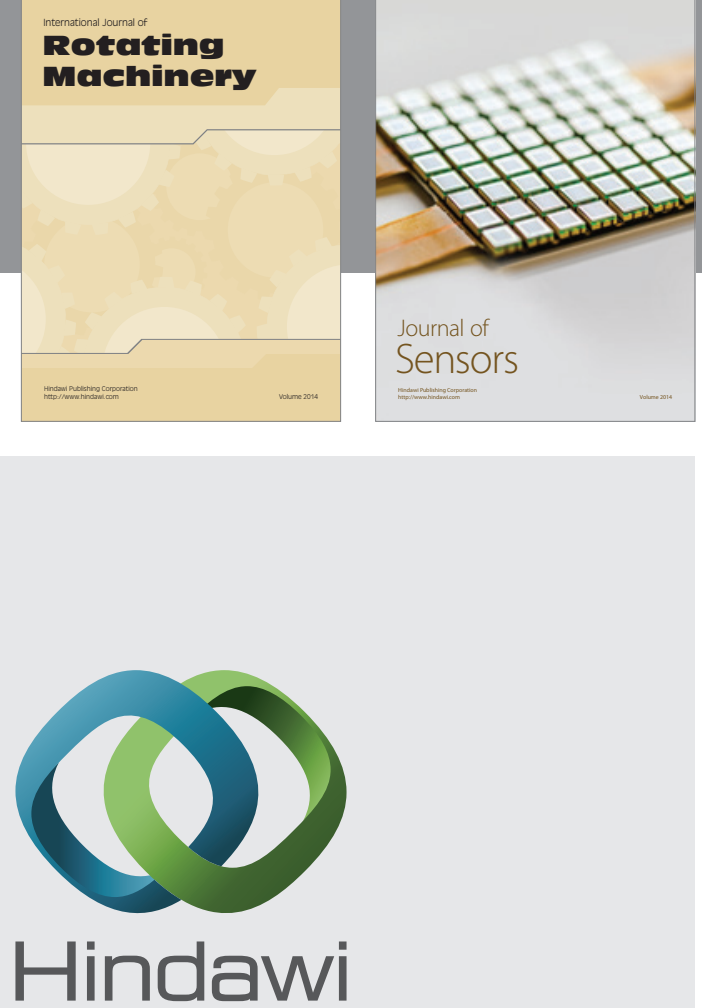

Submit your manuscripts at http://www.hindawi.com
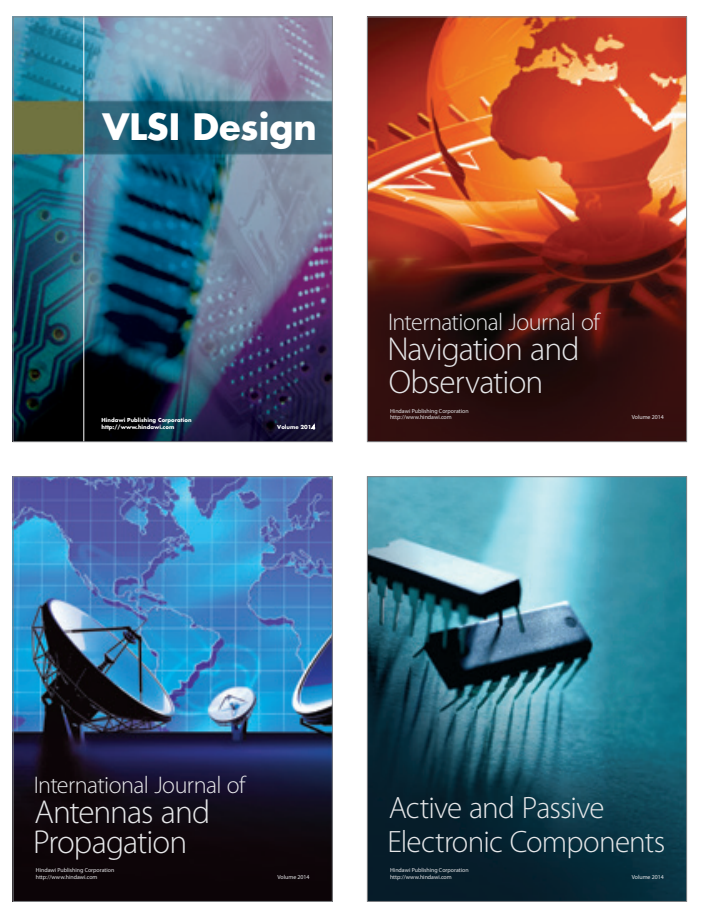
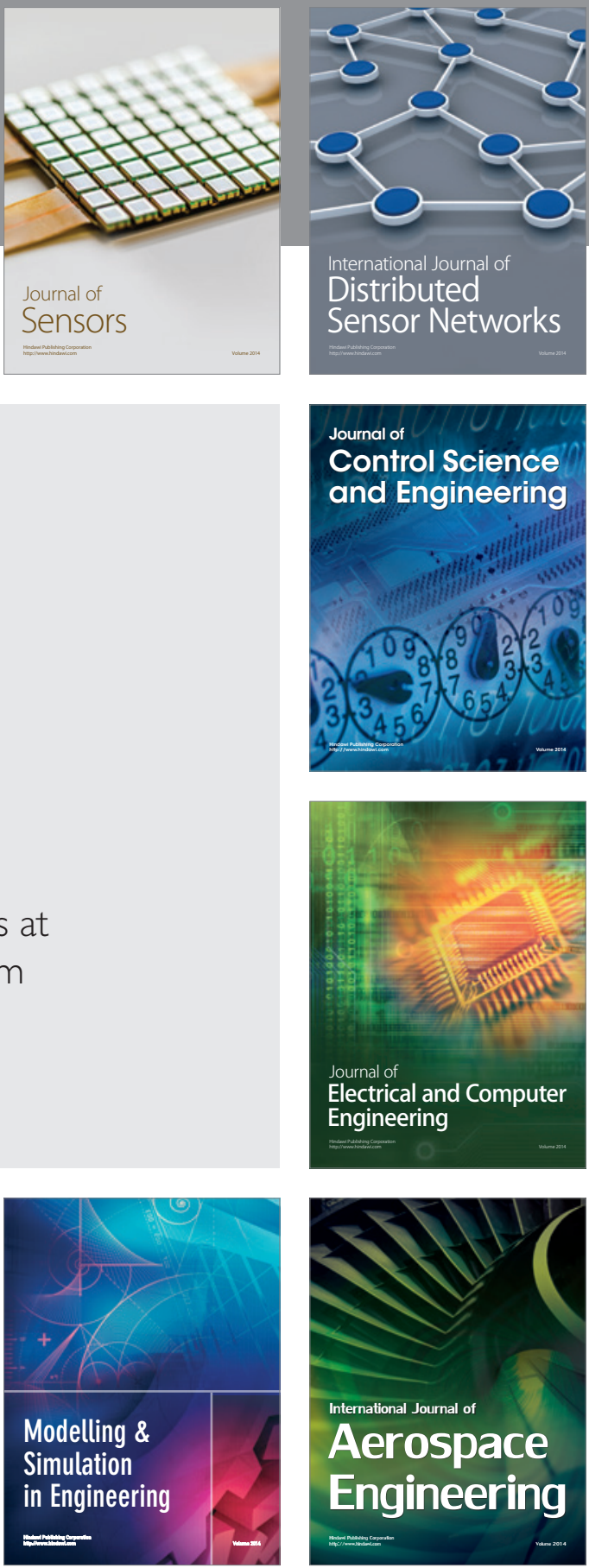

Journal of

Control Science

and Engineering
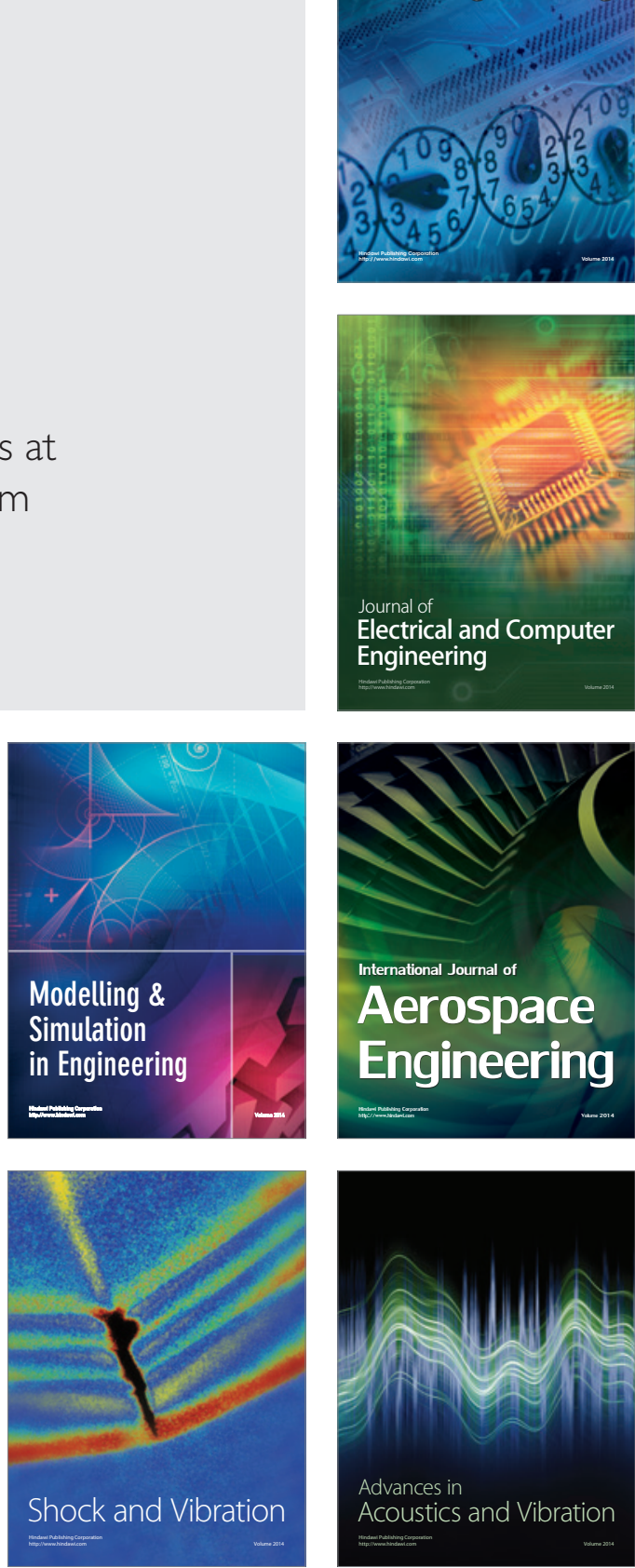